\title{
UMA INVESTIGAÇÃO SOBRE A FOCALIZAÇÃO DO PROGRAMA BOLSA FAMÍLIA E SEUS DETERMINANTES IMEDIATOS
}

\author{
André Portela Souza * \\ Janete Duarte $^{\dagger}$ \\ José de Anchieta Semedo Neves $\ddagger$ \\ Plínio Portela de Oliveira $\S$ \\ Sérgio Ricardo de Brito Gadelha
}

\section{Resumo}

Este estudo tem por objetivo realizar uma investigação sobre a focalização do Programa Bolsa Família (PBF) e seus determinantes imediatos, assim como uma análise quantitativa sobre as famílias beneficiadas. Os resultados econométricos indicam uma relação inversa entre a cobertura do PBF e os níveis de desenvolvimento social e econômico municipais. Há evidências de que municípios com maior qualidade na gestão dos recursos do PBF apresentam percentuais superiores de cobertura. Simulações de políticas sugerem a necessidade de que um direcionamento de políticas para universalização deve envolver esforços tanto para fins de efetivo alcance das famílias elegíveis, mas não beneficiárias, como para redução do vazamento do programa.

Palavras-chave: Programa Bolsa Família; descentralização; focalização; pobreza; desigualdade.

\begin{abstract}
This study aims to conduct an investigation into the targeting of Bolsa Família Program and its immediate determinants, as well as a quantitative analysis of beneficiary families. The econometric results point to an inverse relationship between the Program coverage and the municipal levels of social and economic development. There is evidence that municipalities with more professional management of BFP's resources have a higher coverage. Policies simulations suggest the need to involve efforts both for the purpose to reach eligible but yet not benefited families and for reducing the Program leakage, whether the objective is the universalization.
\end{abstract}

Keywords: Bolsa Familia Program; targeting; decentralization; poverty; inequality.

JEL classification: C31, H53, H77, I38, O15.

DOI: http://dx.doi .org/10.11606/1980-5330/ea168729

\footnotetext{
* Fundação Getúlio Vargas (FGV/SP).

† Secretaria do Tesouro Nacional.

‡ Secretaria do Tesouro Nacional.

$\S$ Secretaria do Tesouro Nacional.

II Secretaria do Tesouro Nacional. E-mail para contato (autor correspondente): sergio.gadelha@fazenda.gov.br.
} 


\section{Introdução}

Embora a literatura sobre federalismo fiscal estabeleça que a renda deve ser redistribuída por um governo central (Musgrave 1971, Oates 1999), nos países em desenvolvimento tem-se tornado prática comum delegar a tarefa de escolher os beneficiários de programas governamentais de redução de pobreza aos governos e comunidades locais, os quais possuem mais informações a respeito da população pobre do que o governo central, de modo que há um incentivo de se usar a informação disponível localmente para melhorar o desempenho desses tipos de programas (Galasso \& Ravallion 2005).

A focalização diz respeito ao direcionamento de recursos e programas para determinados grupos, considerados vulneráveis no conjunto da sociedade. É perfeitamente focalizado o programa que transfere recursos para todas as pessoas elegíveis (Kerstenetzky 2009). Um importante obstáculo à melhoria da focalização dos programas governamentais de transferência de renda para as famílias pobres são os custos elevados que podem estar envolvidos na obtenção de informações precisas sobre rendimentos e necessidades da população local. Por essa razão, a maneira que tem sido sugerida para reduzir o custo é descentralizar a responsabilidade pelo monitoramento e gerenciamento desses programas aos governos locais, sob o argumento de que esses governos são capazes de realizar essa tarefa com maior precisão e efetividade, em termos de custos, do que o governo central. Alega-se que os governos locais são melhores informados sobre a renda dos membros de suas comunidades e, dessa forma, são capazes de identificar as famílias pobres. Por outro lado, as famílias seriam menos capazes de esconder informações sobre seus rendimentos das autoridades governamentais locais, em comparação às autoridades em nível nacional. Uma vez que a pobreza em certa comunidade pode ser caracterizada por diferentes indicadores do que a pobreza em outra comunidade, o sistema descentralizado pode aumentar a eficiência de um programa de redução de pobreza ao permitir que as autoridades governamentais locais determinem o critério de elegibilidade local (Alderman 2002).

Nos últimos anos, os Programas de Transferência Condicionada de Renda (PTCRs), os quais são focalizados às famílias pobres, vem ganhando espaço na agenda de governos, em função dos impactos reais e significativos dessas políticas sociais a esse segmento da população. Em países desenvolvidos, a seleção dos beneficiários desses programas é realizada por meio do método de focalização (targeting) conhecido por means test, no qual somente os indivíduos abaixo de certo limiar de renda são considerados elegíveis. No Brasil, o processo de seleção dos beneficiários do Programa Bolsa Família (PBF) se baseia nesse método, no qual se utiliza um conjunto de informações cruciais na discriminação entre elegíveis e não elegíveis, por exemplo, declarações de renda ou outros critérios de elegibilidade, os quais são verificados (verified means test - VMT) ou não verificados (unverified means test - UMT) pelo governo. Em particular, o VMT é considerado um método de alta precisão ao envolver a verificação da renda declarada por meio do cruzamento de informações bancárias e fiscais dos indivíduos. A seleção dos beneficiários do PBF se aproxima do VMT ao comparar a renda declarada pela família com informações de seus gastos e com os dados da Relação Anual de Informações Sociais (RAIS) do Ministério do Trabalho e Emprego (Tavares et al. 2009).

Todavia, Coady et al. (2005) argumentam que, devido a sua complexidade, o VMT só é possível de ser implementado com um alto grau de formalidade 
entre os elegíveis em termos de declaração de rendimentos e riqueza, de modo que esse método é mais usado em países desenvolvidos. Por outro lado, em países em desenvolvimento, existem incentivos para subdeclaração da renda, já que a verificação das informações de rendimentos por outras fontes é menos confiável, devido ao elevado grau de informalidade entre o público-alvo desses programas sociais de transferência de renda (Tavares et al. 2009, Alatas et al. 2012).

Consequentemente, em nações em desenvolvimento, existe uma ênfase crescente em abordagens metodológicas de focalização que não dependem da observação direta dos rendimentos. Em particular, existem dois tipos de estratégias: proxy means tests (PMT) e focalização baseada na comunidade (community-based targeting). O método PMT, que tem sido utilizado em programas como o Progresa/Oportunidades no México, o Subsídio Único Familiar no Chile, e Familias en Acción na Colômbia, é baseado em avaliação domiciliar que consiste em calcular um escore para cada domicílio por meio de variáveis diretamente observáveis (por exemplo, bens e características demográficas) que sejam correlacionadas com a renda. Esse escore calculado, que serve de proxy para o consumo ou renda das famílias, é utilizado para fins de focalização, pois é comparado com um escore de corte que determinará os indíviduos elegíveis ao programa (ALATAS et al., 2012). Por outro lado, no método de focalização baseado em comunidade, adotado em programas como Bangladesh Food-For Education Program (GALASSO e RAVALLION, 2005) e o Albanian Economic Support Safety Net Program (Alderman 2002), o governo permite que a comunidade, ou parte dela (por exemplo, os líderes locais) selecione os beneficiários. Assim, esses dois métodos procuram resolver o problema de rendimentos não observáveis da seguinte forma: no método PMT, o pressuposto é que os ativos (bens) das famílias são mais difíceis de serem escondidos dos inspetores governamentais do que a renda das famílias; já na focalização baseada na comunidade, o pressuposto é que a riqueza de determinada família é mais difícil de se esconder de seus vizinhos do que do governo (Alatas et al. 2012).

A escolha entre essas duas abordagens é considerada um trade-off entre melhor informação que as comunidades possam ter relacionada às famílias versus o risco de "captura da elite" no processo comunitário. Ao focar em bens (ativos), o método PMT captura o componente permanente do consumo, mas há uma perda de informações sobre choques transitórios ou recentes nesse consumo. Por exemplo, uma família pode cair na pobreza porque um de seus membros tenha ficado doente e não pode trabalhar mas, devido ao fato dessa família morar em uma casa grande, o método PMT ainda irá classificá-la como sendo "não pobre". Os vizinhos, por sua vez, podem conhecer a verdadeira situação financeira de determinada família pela observação regular do estilo de vida dessa família. Se a comunidade percebe que o método PMT não é apropriado, isso pode resultar em falta de legitimidade e instabilidade política (Alatas et al. 2012).

Embora o método de focalização baseado na comunidade permite o uso de melhor informação local, esse método abre também a possibilidade de que as decisões de focalização podem ser baseadas em fatores além da pobreza, tal como definido pelo governo. Isso pode ser devido a discordâncias sobre o significado de pobreza: o governo central avalia as famílias baseado no consumo, ao passo que a função utilidade usada pelas comunidades locais pode incluir outros fatores, tais como potenciais rendimentos de uma família, número de 
dependentes e dimensões de pobreza não relacionadas à renda. Além disso, esse método pode favorecer amigos e parentes das elites, resultando em falta de legitimidade no processo (Alatas et al. 2012).

No caso brasileiro, embora diversos estudos tem indicado a boa gestão do PBF e sua importância na redução da pobreza (Tavares et al. 2009, Soares et al. 2007), há espaço para se propor melhorias em sua focalização no processo de identificação das famílias pobres. O objetivo geral desse estudo é avaliar o grau de focalização de um programa que se pretende ser focalizado, a partir da verificação da heterogeneidade de graus de focalização entre municípios brasileiros, assim como analisar quais variáveis municipais observadas estão sistematicamente associadas aos diferentes graus de focalização para essa heterogeneidade. Para atingir essa finalidade, propõem-se como objetivos específicos: (i) a realização de uma análise espacial para diferentes valores do indicador de focalização proposto, assim como o cálculo dos percentuais de cada um dos componentes desse indicador; (ii) a realização de uma simulação de perfeita focalização do Programa Bolsa Família, sob a hipótese forte de vazamento nulo; (iii) estimação de um modelo logit visando investigar os determinantes imediatos da focalização desse programa; (iv) a realização de simulações de políticas, visando analisar a sensibilidade sobre a cobertura do PBF decorrente de variações hipotéticas em determinadas variáveis.

Esse estudo contribui à literatura ao mostrar não apenas a grande heterogeneidade existente no tocante à focalização do Programa Bolsa Família nos diferentes municípios, como também por apresentar evidências empíricas da existência de uma relação inversa entre a cobertura do PBF e os níveis de desenvolvimento social e econômico municipais. Além disso, há evidências de que municípios com maior qualidade na gestão dos recursos do programa apresentam percentuais superiores de cobertura. Simulações de políticas sugerem a necessidade de que um direcionamento de políticas para universalização deve envolver esforços tanto para fins de efetivo alcance das famílias elegíveis, mas não beneficiárias, como para redução do vazamento do programa.

\section{O Programa Bolsa Família}

A gestão do PBF é descentralizada e compartilhada entre a União, Estados, Distrito Federal e Municípios, em trabalho conjunto para aperfeiçoar, ampliar e fiscalizar a execução do programa, instituído pela Lei ${ }^{\circ}$. 10.836/2004 (http://www.planalto.gov.br/ccivil_03/_Ato2004-2006/2004/Lei/L10.836.htm) e regulamentado pelo Decreto $\mathrm{n}^{\circ}$ 5.209/2004 (http://www.planalto.gov.br/ ccivil_03/_Ato2004-2006/2004/Decreto/D5209.htm). A seleção das famílias é feita com base nas informações registradas pelo município no Cadastro Único para Programas Sociais do Governo Federal (ht tp : / www . mds . gov . br / bolsafa milia/resolveuid/1169e4d98311fe31e82e6712f9aa7c4a), instrumento de coleta de dados que tem como objetivo identificar todas as famílias de baixa renda existentes no Brasil. Com esses dados, o MDS seleciona, de forma automatizada, as famílias que serão incluídas no PBF. No entanto, o cadastramento não implica a entrada imediata das famílias no programa e o recebimento do benefício.

Os benefícios financeiros definidos pela Lei $\mathrm{n}^{\circ}$. 10.836/2004 (http: //www. mds.gov.br/bolsafamilia/beneficios/resolveuid/40f258f6658844da 10d984f 487 2c60b9/download) são transferidos mensalmente às famílias beneficiárias, consi- 
derando-se a renda mensal per capita da família, o número de crianças e adolescentes até 17 anos e a existência de gestantes e nutrizes. A Tabela 1 apresenta a evolução dos critérios de elegibilidade e benefícios do PBF entre os anos 2004 a 2012.

\section{Medida de Focalização}

Nesse estudo, será adotada como medida de focalização, a metodologia proposta por Anuatti-Neto et al. (2001), e que já foi aplicada empiricamente ao nível estadual por Tavares et al. (2009):

$$
I F=\alpha\left[P_{I}-P_{E}\right]+(1-\alpha)\left[N P_{E}-N P_{I}\right]
$$

em que $P_{I}, P_{E}, N P_{I}$ e $N P_{E}$ são variáveis de focalização (targeting) da política de redução da pobreza, sendo definidas da seguinte forma:

- $P_{I}=\tilde{P}_{I} / E$ corresponde à proporção de domicílios pertencentes ao públicoalvo (isto é, quantidade de famílias elegíveis, $E$ ) corretamente incluídos no programa, ou seja, trata-se da inclusão correta ou cobertura do PBF;

- $P_{E}=\tilde{P_{E}} / E$ corresponde à proporção de domicílios pertencentes ao públicoalvo erroneamente excluídos do programa, conhecida também como exclusão indevida ou erro tipo I;

- $N P_{I}=N P_{I} / N E$ corresponde à proporção de domicílios não pertencentes ao público-alvo (isto é, quantidade de famílias inelegíveis, $N E$ ) erroneamente incluídos no programa, conhecida também como inclusão indevida, vazamentos ou erro tipo II;

- $N P_{E}=N \tilde{P}_{E} / N E$ corresponde à proporção de domicílios não pertencentes ao público-alvo corretamente excluídos no programa, ou seja, a exclusão correta;

- $\alpha \in[0 ; 1]$ é uma variável discricionária que, uma vez escolhido o seu valor pelo policymaker, atribuirá pesos ao alcance e à precisão do PBF.

Como pode ser visto, IF $\in[-1 ; 1]$, e quanto mais próximo esse indicador estiver de 1, melhor o grau de focalização. Assim, a medida de focalização adotada considera, a princípio, tanto o alcance quanto a precisão do PBF. O parâmetro $\alpha$ é o peso atribuído ao alcance, ao passo que $(1-\alpha)$ é atribuído à precisão. Para calcular o valor do IF, podem-se escolher valores arbitrários para o parâmetro $\alpha$, estabelecendo importâncias relativas para os dois critérios de focalização, como é feito em Tavares et al. (2009).

Kerstenetzky (2009) (p.64) argumenta que, se os tomadores de decisão escolherem minimizar o erro de inclusão (erro tipo II), eles provavelmente terão de aceitar operar um programa menos extenso e acabarão por incorrer no erro de exclusão (erro tipo I), um resultado paradoxal se considerar que o objetivo de tais programas é a eliminação da pobreza. Se, inversamente, buscarem minimizar o erro de exclusão, perseguirão a expansão do programa e enfrentarão o risco de incluir pessoas não elegíveis. Se, finalmente, decidirem acertar o alvo, terão de despender recursos para manter um cadastro confiável e atualizado de todas as pessoas elegíveis, o que representaria uma 
Tabela 1: Evolução dos critérios de elegibilidade e benefícios do PBF, 2004-2012, em R\$1,00

\begin{tabular}{|c|c|c|c|c|c|c|c|c|c|c|c|}
\hline \multicolumn{3}{|c|}{ Critérios } & $2004^{(1)}$ & $2005^{(1)}$ & $2006^{(2)}$ & $2007^{(3)}$ & $2008^{(4)}$ & $2009^{(5)}$ & $2010^{(5)}$ & $2011^{(6)}$ & $2012^{(6)}$ \\
\hline \multirow{2}{*}{\multicolumn{2}{|c|}{$\begin{array}{l}\text { Elegibilidade } \\
\text { (Renda Familiar Mensal } \\
\text { per capita) }\end{array}$}} & $\begin{array}{l}\text { Extremamente } \\
\text { Pobres }^{(a)}\end{array}$ & 50,00 & 50,00 & 60,00 & 60,00 & 60,00 & 70,00 & 70,00 & 70,00 & 70,00 \\
\hline & & Pobres ${ }^{(b)}$ & 100,00 & 100,00 & 120,00 & 120,00 & 120,00 & 140,00 & 140,00 & 140,00 & 140,00 \\
\hline \multirow{6}{*}{ Benefícios } & Básico & \multirow{3}{*}{$\begin{array}{l}\text { Extremamente } \\
\text { Pobres }^{(a)}\end{array}$} & 50,00 & 50,00 & 50,00 & 58,00 & 62,00 & 68,00 & 68,00 & 70,00 & 70,00 \\
\hline & Variável & & $\begin{array}{l}15,00 \\
\left(\begin{array}{lll}0 & a & 14\end{array}\right) \\
\end{array}$ & $\begin{array}{l}15,00 \\
\left(\begin{array}{lll}0 & a & 14\end{array}\right)\end{array}$ & $\begin{array}{l}15,00 \\
\left(\begin{array}{lll}0 & a & 14\end{array}\right) \\
\end{array}$ & $\begin{array}{l}18,00 \\
\left(\begin{array}{lll}0 & a & 14\end{array}\right) \\
\end{array}$ & $\left.\begin{array}{lll}20, & 00 \\
(0 & a & 15\end{array}\right)$ & $\begin{array}{l}22,00 \\
\left(\begin{array}{lll}0 & a & 15\end{array}\right) \\
\end{array}$ & $\begin{array}{l}22,00 \\
\left(\begin{array}{llll}0 & a & 15\end{array}\right) \\
\end{array}$ & $\begin{array}{l}32,00 \\
\left(\begin{array}{lll}0 & a & 15\end{array}\right) \\
\end{array}$ & $\begin{array}{l}32,00 \\
\left(\begin{array}{lll}0 & a & 15\end{array}\right) \\
\end{array}$ \\
\hline & BVJ & & - & - & - & - & $\begin{array}{c}30,00 \\
(16 \text { a } 17)\end{array}$ & $\begin{array}{c}33,00 \\
(16 \quad a \quad 17)\end{array}$ & $\begin{array}{c}33,00 \\
(16 \text { a } 17)\end{array}$ & $\begin{array}{c}38,00 \\
(16 \text { a } 17)\end{array}$ & $\begin{array}{c}38,00 \\
(16 \quad a \quad 17)\end{array}$ \\
\hline & Variável & \multirow{3}{*}{ Pobres ${ }^{(b)}$} & $\begin{array}{l}15,00 \\
\left(\begin{array}{lll}0 & a & 14\end{array}\right)\end{array}$ & $\begin{array}{l}15,00 \\
\left(\begin{array}{lll}0 & a & 14\end{array}\right)\end{array}$ & 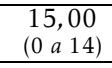 & $\begin{array}{ll}18,00 \\
(0, a & 14) \\
\end{array}$ & $\begin{array}{ll}20, & 00 \\
\left(\begin{array}{llll}0 & a & 15\end{array}\right) \\
\end{array}$ & $\begin{array}{c}22,00 \\
\left(\begin{array}{lll}0 & a & 15\end{array}\right)\end{array}$ & $\begin{array}{c}22,00 \\
\left(\begin{array}{lll}0 & a & 15\end{array}\right) \\
\end{array}$ & $\begin{array}{l}32,00 \\
\left(\begin{array}{lll}0 & a & 15\end{array}\right) \\
\end{array}$ & $\begin{array}{c}32,00 \\
\left(\begin{array}{lll}0 & a & 15\end{array}\right)\end{array}$ \\
\hline & BVJ & & - & - & - & - & $\begin{array}{c}30,00 \\
\left(\begin{array}{lll}16 & a & 17\end{array}\right)\end{array}$ & $\begin{array}{c}33,00 \\
(16 \text { a } 17) \\
\end{array}$ & $\begin{array}{c}33,00 \\
(16 \text { a }\end{array}$ & $\begin{array}{l}38,00 \\
(16 \text { a } 17)\end{array}$ & $\begin{array}{c}38,00 \\
(16 \text { a } \\
\end{array}$ \\
\hline & BSP & & & & & & & & & & Variável $^{(7)}$ \\
\hline
\end{tabular}

Nota: Elaboração dos autores. (a) linha de pobreza extrema; (b) linha de pobreza. O MDS trabalha com cinco tipos de benefícios do PBF: (i) Benefício Básico ou Fixo (no valor de R\$ 70, concedidos apenas a famílias extremamente pobres, com renda per capita igual ou inferior a R\$ 70); (ii) Benefício

Variável (no valor de $\mathrm{R} \$ 32$, concedidos pela existência na família de crianças de zero a 15 anos, gestantes e/ou nutrizes - limitado a cinco benefícios por família); (iii) Benefício Variável Vinculado ao Adolescente (BVJ), no valor de R\$38, concedidos pela existência na família de jovens entre 16 e 17 anos - limitado a dois jovens por família; e (iv) Benefício para Superação da Extrema Pobreza (BSP), com valor correspondente ao necessário para que todas as famílias beneficiárias do PBF atinjam pelo menos os $\mathrm{R} \$ 70,00$ de renda mensal por pessoa.

1 - Lei $n^{\circ} 10.836 / 2004$ e Decreto $n^{\circ} 5.209 / 2004$. Crianças (R\$ 15,00 a R\$ 45,00);

2 - Decreto $n^{\circ} 5.749 / 2006$. Crianças (R\$15,00 a R\$45,00);

3 - Decreto $n^{\circ} 6.157 / 2007$. Crianças ( $\$$ \$ 18,00 a $R \$ 54,00$ ) e Jovens ( $\$$ \$ 30,00 a $\left.R \$ 60,00\right)$;

4 - Lei $\mathrm{n}^{\circ} 11.692 / 2008$ e Decreto $\mathrm{n}^{\circ}$ 6.491/2008. Crianças ( $\mathrm{R} \$ 20,00$ a $\left.\mathrm{R} \$ 60,00\right)$ e Jovens ( $\mathrm{R} \$ 30,00$ a $\left.\mathrm{R} \$ 60,00\right)$;

5 - Decreto $n^{\circ} 6.917 / 2009$. Crianças ( $R \$ 22,00$ a $R \$ 66,00$ ) e Jovens (R 33,00 a $R \$ 66,00$ );

6 - Decreto $n^{\circ} 7.447 / 2011$ e Decreto $n^{\circ} 7.494 / 2011$. Crianças (R\$32,00 a $R \$ 160,00$ ) e Jovens (R\$38,00 a R\$ 76,00);

7 - Medida Provisória $n^{\circ} 570 / 2012$, convertida na Lei $n^{\circ} 12.722 / 2012$ (para famílias com crianças entre 0 e 6 anos e renda per capita igual ou inferior a R\$ 70,00 - implementado em junho de 2012 na Ação Brasil Carinhoso); Medida Provisória n ${ }^{\circ}$ 590/2012, convertida na Lei n $12.817 / 2013$ (para

famílias com crianças entre 0 e 15 anos e renda per capita igual ou inferior a R\$ 70,00 - implementado em dezembro de 2012 no Plano Brasil Sem

Miséria). A partir de março de 2013, todas as famílias beneficiárias do PBF com renda per capita igual ou inferior a R $\$ 70,00$ passaram a fazer jus à complementação do BSP, independentemente da existência de jovens de 0 a 15 anos na família. 
diversificação de recursos que, dado o orçamento, poderiam ser mais proveitosamente utilizados na expansão do programa. Portanto, do ponto de vista da equidade, a escolha de uma noção secundária, praticável, de eficiência é não neutra. Todavia, a literatura empírica tem mostrado que o trade-off existente entre o erro tipo I (exclusão indevida) e o erro tipo II (inclusão indevida) tem sido provocado por uma série de motivos, dentre eles, os erros de medição da renda no momento do cadastramento, a volatilidade da renda (particularmente, a renda dos indivíduos mais pobres) e o comportamento estratégico dos indivíduos e das famílias (Tavares et al. 2009, Soares et al. 2009). Como um problema inicial trataria a respeito de uma combinação ideal entre esses dois tipos de erros, seria interessante que o policymaker conhecesse, a priori, como esses índices evoluem à medida que o programa passasse a contemplar um número maior de beneficiários.

Segundo Anuatti-Neto et al. (2001) e Tavares et al. (2009), o IF avalia a efetividade geral da regra de seleção ao considerar simultaneamente medidas de alcance $\left(P_{I}-P_{E}\right)$ e de precisão $\left(N P_{E}-N P_{I}\right)$ do $P B F$. Em programas de combate à pobreza focalizados, o esforço dos policymakers está em minimizar a exclusão indevida ou erro tipo I (ou seja, maximizar a cobertura), assim como minimizar a inclusão indevida ou erro tipo II (ou seja, minimizar o vazamento). Visando obter os valores do indicador de focalização $(I F)$ e de seus componentes $\left(P_{I}, P_{E}, N P_{I}, N P_{E}\right)$ para a análise das medidas de alcance e de precisão do PBF, é necessário que haja uma variável que represente a renda familiar per capita antes do recebimento dos recursos do PBF para fins de elegibilidade das famílias ao programa. A construção dessa nova variável de renda familiar per capita ex ante encontra-se descrita no apêndice deste estudo. Nesse estudo, foram utilizados os microdados dos questionários aplicados à amostra do Censo Demográfico 2010, realizado pelo Instituto Brasileiro de Geografia e Estatística (IBGE), qual representava $11 \%$ dos domicílios (cerca de 6,4 milhões), e o questionário aplicado proporcionou informações quanto à inserção ou não dos residentes no $\mathrm{PBF}^{1}$.

Todavia, é importante destacar que a estimativa de domicílios beneficiados com os recursos do PBF obtida usando os dados do Censo Demográfico 2010 (9,0 milhões) difere do número divulgado pelo Ministério do Desenvolvimento Social e Combate à Fome (12,7 milhões). Muito provavelmente, as maiores fontes das diferenças encontradas podem residir em um dos seguintes fatores, ou na combinação deles: (a) Levantamentos com períodos de referência distintos (o Censo Demográfico, para a pergunta sobre rendimentos, utilizou como referência o mês de julho de 2010); (b) Distinções de abordagem: enquanto o Censo Demográfico é uma pesquisa domiciliar, que tem

\footnotetext{
${ }^{1}$ No Censo Demográfico 2010 foram utilizados o questionário básico e o questionário da amostra. Nesses, o rendimento mensal habitual foi investigado para todas as pessoas com 10 anos ou mais de idade. No questionário básico, o rendimento mensal habitual foi pesquisado em um único quesito, abrangendo os rendimentos de todas as fontes. No questionário da amostra essa informação é obtida por meio da soma dos rendimentos obtidos em três quesitos que captaram: (i) o rendimento mensal habitual do trabalho principal da semana de referência; (ii) o rendimento mensal habitual dos demais trabalhos da semana de referência; e (iii) o rendimento mensal habitual oriundo de outras fontes (soma dos rendimentos de: aposentadoria e pensão de instituto de previdência oficial, Programa Social Bolsa Família, Programa de Erradicação do Trabalho Infantil (PETI), outros programas sociais e transferências, aposentadoria e pensão da previdência privada, aluguel, juros de caderneta de poupança e de outras aplicações financeiras, etc.) do mês de referência. Para fins deste estudo, foi utilizado o conceito de domicílios do Censo Demográfico 2010 como proxy para famílias.
} 
mecanismos próprios de realização da entrevista (basta que um morador do domicílio, com suficiente conhecimento das características dos demais, esteja presente no momento da entrevista para prestar as informações sobre todos ali residentes), o levantamento do MDS é cadastral e, supõe-se, toma por base as informações do Cadastro Único e do banco de dados que regula o PBF; (c) As variáveis associadas ao tema rendimento são, tradicionalmente, das mais difíceis de investigar em qualquer pesquisa domiciliar, por motivos que vão da natural contenção das pessoas ao falar sobre seus rendimentos com "estranhos" até a desinformação existente dentro do próprio domicílio, quando o informante não é a própria pessoa que aufere os rendimentos indagados; e (d) As diferenças com origem nos conceitos de domicílio no Censo Demográfico $^{2}$ e família beneficiada do $\mathrm{MDS}^{3}$. Por fim, cabe registrar que o processo censitário, frente ao levantamento cadastral, tendo as diversas características enumeradas, apresenta captação menos eficaz desse tipo de variável.

As Figuras 1 a 3 a seguir mostram a distribuição espacial do indicador de focalização, para diferentes valores do fator de ponderação $(\alpha)$, os percentuais de cada um dos componentes do indicador de focalização $\left(P_{I}, N P_{I}, P E e N P E\right)$. A Figura 1 considera $\alpha=0$, situação que descreve um peso maior para a medida de precisão do $\mathrm{PBF},\left(N P_{E}-N P_{I}\right)$. O artifício de subtrair-lhe o complementar apenas amplia a variabilidade de $[0 ; 1]$ para $[-1 ; 1]$. É possível observar que, em termos de precisão, a focalização do PBF é maior nos municípios das regiões Sul e Sudeste, apesar de se destacar alguns municípios no Centro-Oeste. Pode-se argumentar que, nos municípios dessas regiões, os gestores do PBF possuem mais recursos (por exemplo, recursos humanos, materiais e financeiros) à disposição para realizar a correta exclusão de famílias inelegíveis.

Por sua vez, a Figura 2 considera $\alpha=1$, situação que descreve um peso maior à medida de alcance do $\mathrm{PBF},\left(P_{I}-P_{E}\right)$. Mais uma vez, a subtração pelo seu complementar amplia a variabilidade. Assim, em termos de alcance, a focalização do PBF é maior para os municípios das regiões Norte e Nordeste, onde reside uma maior parcela das famílias elegíveis e beneficiárias dos recursos do PBF.

Finalmente, a Figura 3 considera $\alpha=0,5$, que confere iguais pesos à precisão e ao alcance. Note que há uma maior inclusão de municípios da região Nordeste, em detrimento de municípios das regiões Sul e Sudeste. Soares et al. (2009) argumentam que a expansão de programas focalizados tende a melhorar a cobertura entre a população mais pobre, mas à custa de uma piora nos indicadores de focalização.

\footnotetext{
${ }^{2}$ De acordo com o IBGE, família é o conjunto de pessoas ligadas por laços de parentesco, dependência doméstica ou normas de convivência, residente na mesma unidade domiciliar, ou pessoa que mora só em uma unidade domiciliar. Entende-se por dependência doméstica a relação estabelecida entre a pessoa de referência e os empregados domésticos e agregados da família, e por normas de convivência as regras estabelecidas para o convívio de pessoas que moram juntas, sem estarem ligadas por laços de parentesco ou dependência doméstica. Consideram-se como famílias conviventes as constituídas de, no mínimo, duas pessoas cada uma, que residam na mesma unidade domiciliar (domicílio particular ou unidade de habitação em domicílio coletivo). Conforme informado no Censo Demográfico 2010, domicílio "é o local estruturalmente separado e independente que se destina a servir de habitação a uma ou mais pessoas, o que esteja sendo utilizado como tal".

${ }^{3}$ Para fins de Cadastro Único do PBF, família é a unidade nuclear composta por uma ou mais pessoas, eventualmente ampliada por outras que contribuam para o rendimento ou tenham suas despesas atendidas por ela, todas moradores em um mesmo domicílio. Já domicílio é o local que serve de moradia à família (Portaria MDS nº 177, de 16/06/2011).
} 


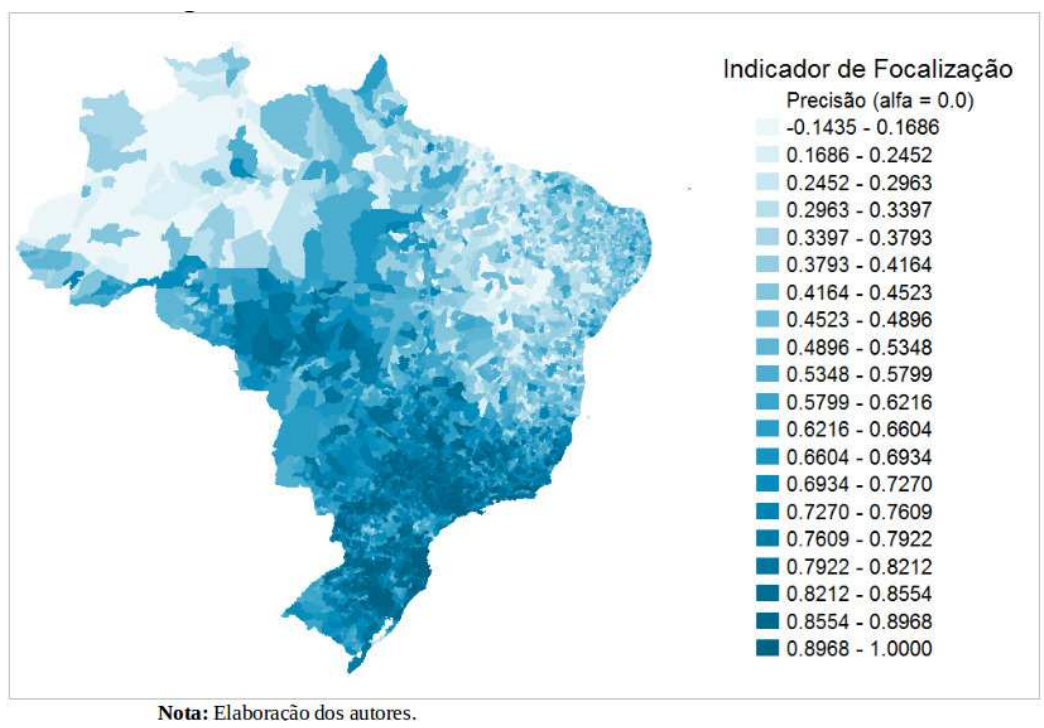

Nota: Elaboração dos autores.

Figura 1: Precisão do PBF, 2010

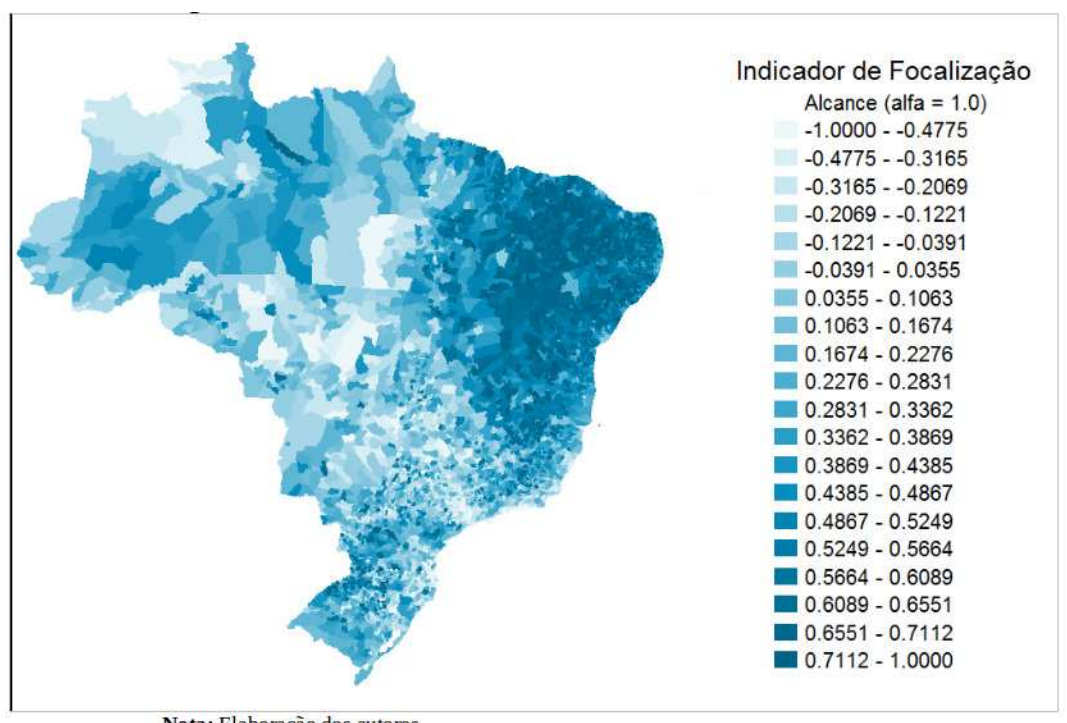

Nota: Elaboraçào dos autores.

Nota: Elaboração dos autores.

Figura 2: Alcance do PBF, 2010 


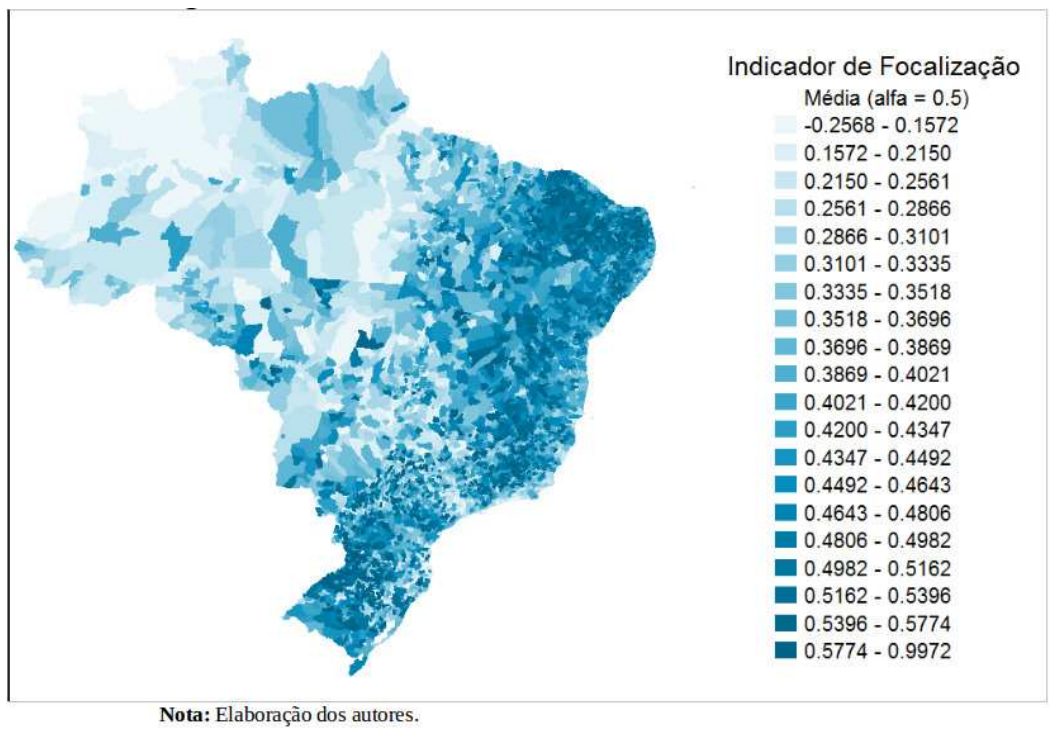

Nota: Elaboração dos autores.

Figura 3: Média entre alcance e precisão do PBF, 2010

A Tabela 2 exibe as estimativas feitas a partir dos microdados da amostra do Censo 2010 e da aproximação da renda familiar per capita ex-ante, bem como estimativas realizadas por Soares et al. (2009) a partir dos microdados da Pesquisa Nacional por Amostra de Domicílios (PNAD) para os anos 2004 e 2006. Estima-se que, em 2010, a proporção de domicílios elegíveis erroneamente excluídos do PBF (ou seja, o erro tipo I) foi de 39,0\%, ao passo que a proporção de domicílios inelegíveis erroneamente incluídos no PBF (isto é, o erro tipo II) foi de $21,9 \%$. Ocorrem, portanto, dois movimentos distintos em relação aos dados de 2006.

Tabela 2: Comparativo de resultados apresentados na literatura

\begin{tabular}{lccc}
\hline \multirow{2}{*}{ Variáveis } & CESEF/STN & \multicolumn{2}{c}{ Soares et al. (2009) } \\
\cline { 3 - 4 } & Censo 2010 & PNAD2006 & PNAD2004 \\
& $61,0 \%$ & $56,3 \%$ & $42,9 \%$ \\
\hline$P_{I}$ & $39,0 \%$ & $43,7 \%$ & $57,1 \%$ \\
$P_{E}$ (Erro Tipo I) & $21,9 \%$ & $9,8 \%$ & $6,4 \%$ \\
$N P_{I}$ (Erro Tipo II) & $78,1 \%$ & $90,2 \%$ & $93,6 \%$ \\
$N P_{E}$ &
\end{tabular}

Nota: Elaboração dos autores.

1 - Censo Demográfico 2010, divulgado em 2012;

2 - PNAD 2006. Dados percentuais obtidos a partir da Tabela 4 em Soares et al. (2009);

3 - PNAD 2004. Dados percentuais obtidos a partir da Tabela 4 em Soares et al. (2009).

Primeiro, há uma melhora no alcance do programa, evidenciada pela diminuição do erro do tipo I de $43,7 \%$ para $39,0 \%$. Dessa forma, uma maior proporção das famílias elegíveis passam a ser incluídas como beneficiárias. Por outro lado, há uma considerável deterioração da precisão do PBF, percebida pelo aumento do erro do tipo II de $9,8 \%$ para $21,9 \%$, de forma que mais 
famílias não elegíveis são incluídas como beneficiárias (maior presença de vazamentos).

Esses movimentos em sentidos contrários dos erros do tipo I e II de 2006 a 2010, quando analisados conjuntamente, podem nos levar a uma interpretação de que, a fim de aumentar o alcance do programa, permite-se um maior nível de vazamentos. Ficaria assim evidente a existência de um trade-off entre alcance e precisão.

Os gráficos da Figura 4 a seguir analisam a distribuição acumulada das famílias beneficiárias do PBF. O Gráfico 1 descreve a distribuição acumulada, para o Brasil, das famílias beneficiárias do PBF em 2010. Estima-se que apenas $50,45 \%$ das famílias naquele ano pertenciam efetivamente à faixa de renda estabelecida para o público alvo (até $\mathrm{R} \$ 140$ per capita). Outras 15,28\% recebiam entre R\$140,01 e R\$ 200 (per capita), enquanto 4,48\% das famílias recebiam acima de R\$ 510 per capita (salário mínimo vigente em 2010).
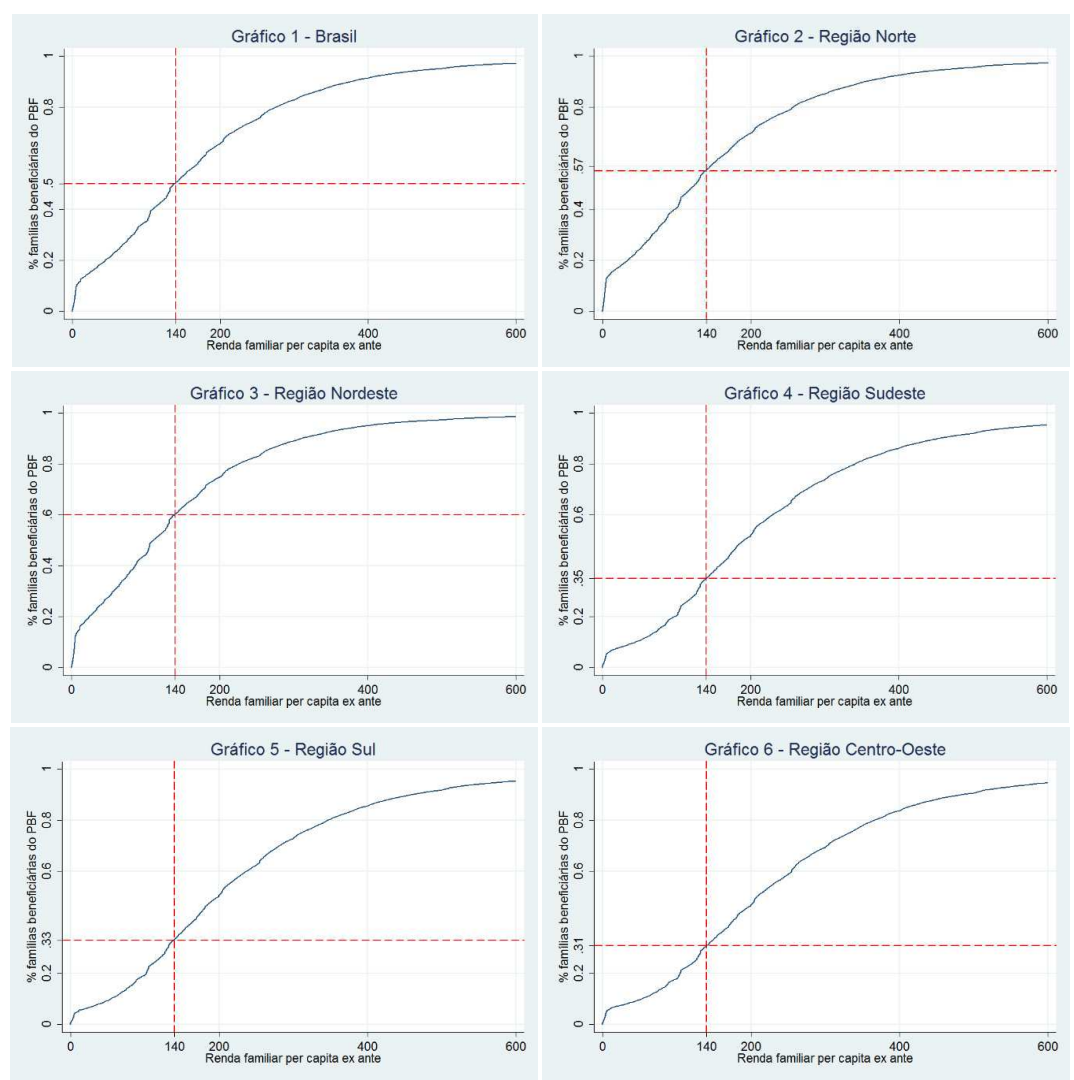

Nota: Elaboração dos autores.

Figura 4: Distribuição acumulada das famílias beneficiárias do PBF, 2010

Nos Gráficos 2 a 6 são dispostas as distribuições acumuladas para as grandes regiões brasileiras. É interessante notar que as distribuições acumuladas das regiões Norte e Nordeste crescem mais rapidamente do que observado nas demais regiões, isto é, parcelas maiores dos beneficiários nessas regiões tem renda familiar per capita mais baixa. Observa-se, portanto, que a focalização, 
em termos de medida de alcance do PBF, é maior nos municípios das regiões Norte e Nordeste, em consonância com a análise feita na Figura 2 anterior. Por outro lado, em termos de medida de precisão, a focalização é maior nos municípios das regiões Sul, Sudeste e Centro-Oeste, conforme verificado na Figura 1 anterior.

\section{Descrição das Variáveis e Estratégia Empírica}

\subsection{Descrição da Variável Dependente e da Metodologia}

Segundo o conceito de indicador de focalização tratado neste estudo, sejam as famílias elegíveis definidas como sendo $E=\tilde{P}_{I}+\tilde{P_{E}}$, ao passo que as famílias inelegíveis são definidas como sendo $N E=N \tilde{P P}_{I}+N \tilde{P}_{E}$. Além disso, as famílias beneficiárias são definidas como sendo $B=\tilde{P}_{I}+N \tilde{P P}_{I}$, isto é, os benefícios do PBF são distribuídos entre famílias elegíveis e inelegíveis ou, dito de outro modo, $B$ é o total dos benefícios distribuídos em um dado município. Portanto, a cobertura do $\operatorname{PBF}\left(y_{i}=P_{I}\right)$ pode ser expressa por:

$$
\begin{array}{r}
P_{I}=\frac{\tilde{P_{I}}}{E}=\frac{\left(B-N P_{I}\right)}{E}=\frac{B}{E}-\frac{\tilde{N P_{I}}}{E}=\frac{B}{E}-\frac{\tilde{N P_{I}}}{E} \times \frac{B}{B}=\frac{B}{E}- \\
\frac{\tilde{N P_{I}}}{B} \times \frac{B}{E}=\frac{B}{E}\left(1-\frac{\tilde{N P_{I}}}{B}\right)=\frac{B}{E}\left(1-\frac{N P_{I}}{B} \times \frac{N E}{N E}\right) \\
=\frac{B}{E}\left(1-\frac{\tilde{N P_{I}}}{N E} \times \frac{N E}{B}\right)=\frac{B}{E}\left(1-N P_{I} \times \frac{N E}{B}\right)
\end{array}
$$

em que $\frac{N P_{I}}{B}$ é a proporção de benefícios desperdiçada com famílias inelegíveis.

Existe, portanto, uma identidade que relaciona a cobertura $\left(P_{I}\right)$ ao vazamento $\left(N P_{I}\right)$ e ao aporte de recursos relativo à população alvo $\left(\frac{B}{E}\right)$. De fato, dada a quantidade de benefícios distribuída em um município e sua estrutura populacional dada por $E$ e $N E$, a cobertura será tão maior quanto menor for o vazamento desses benefícios expresso como proporção da população inelegível $\left(N P_{I}\right)$, o que fica evidente na Equação (2). Da mesma forma, para um dado nível de vazamento e estrutura populacional, recursos adicionais implicam uma cobertura maior. Vale lembrar que, considerando constante no curto prazo a estrutura populacional, o aporte relativo representa uma variável de política pública, de caráter eminentemente exógeno.

A identidade acima permite concluir que dados (i) o aporte relativo de recursos (B/E) e (ii) a estrutura populacional, a determinação da focalização implica a determinação do alcance (e vice-versa). Por esse motivo, a investigação sobre os determinantes da focalização considera como variável dependente apenas a cobertura.

Além disso, considerando o caráter exógeno do aporte relativo, aos regressores que serão considerados neste estudo resta o vazamento como único canal de transmissão de sua influência sobre a cobertura. Para um dado aporte de recursos e estrutura populacional, os regressores determinarão a cobertura do programa por meio de sua influência sobre o vazamento.

Como o aporte relativo tem papel fundamental na determinação da cobertura, além de representar uma variável de política extremamente relevante para simulação dos efeitos da ampliação do programa, será incluída como variável de controle. 
O problema de pesquisa envolve o entendimento do processo estocástico associado à variável proporção de domicílios elegíveis corretamente incluídos no $\operatorname{PBF}\left(P_{I}\right)$. Essa variável pode ser entendida como a realização de um experimento com distribuição binomial, composta de $E$ experimentos de Bernoulli, ou seja, cada família elegível corresponde a um experimento no qual os eventos possíveis são sua inclusão (sucesso) ou exclusão do programa (fracasso). Partindo da hipótese de que cada família elegível tem a mesma probabilidade de ser incluída, tem-se que a probabilidade de sucesso é igual à cobertura esperada naquele município. Assim, será possível modelar a cobertura esperada a partir da probabilidade de inclusão de uma família elegível no programa.

Assim, define-se a variável $y_{i}$, passível de observação binária (1, se a família elegível é incluída, ou 0 , caso contrário). Sua modelagem exige uma aproximação por métodos que ponderam sua natureza binária. Dentre os mais utilizados, destacam-se o Modelo Probabilístico Linear (MPL), o Probit e o logit. Neste estudo, utiliza-se o terceiro método. Os resultados oriundos da aplicação desses modelos permite entender como determinadas variáveis explicativas $\left(x_{i}\right)$ estão associadas à probabilidade de ocorrência de sucesso do evento de interesse (no nosso caso, $y_{i}=1$ ).

De forma a derivar o modelo probabilístico, hipotetiza-se a existência de uma variável latente (não observada) descrita por uma equação de medida, de forma que sua relação com a variável observada pode ser assim representada:

$$
y^{*}=x \beta+\varepsilon
$$

$\mathrm{e}$

$$
y_{i}=\left\{\begin{array}{lll}
1 & \text { se } & y_{i}^{*}>0 \\
0 & \text { se } & y_{i}^{*} \leq 0
\end{array}\right.
$$

Nessa modelagem, a probabilidade de sucesso de inclusão de um domicílio elegível pode ser assim expressa:

$$
\operatorname{Prob}\left(y_{i}=1 \mid x_{i}\right)=\operatorname{Prob}\left(y_{i}^{*}>0 \mid x_{i}\right)=\operatorname{Prob}\left(x_{i} \beta+\varepsilon_{i}>0 \mid x_{i}\right)=F\left(x_{i} \beta\right)=\frac{e^{x_{i} \beta}}{1+e^{x_{i} \beta}}
$$

em que $F($.$) é a função de distribuição acumulada de \varepsilon$. No caso do modelo logit, assumimos uma função densidade logística, com média 0 e variância $\pi / 3$. Note que:

$$
\frac{P\left(y_{i}=1 \vee x_{i} \beta\right)}{P\left(y_{i}=0 \vee x_{i} \beta\right)}=\frac{\frac{e^{x_{i}^{\prime} \beta}}{1+e^{x_{i}^{\prime} \beta}}}{\frac{1}{1+e^{x_{i}^{\prime} \beta}}}=e^{x_{i}^{\prime} \beta} \Longrightarrow \ln \left(\frac{P\left(y_{i}=1 \vee x_{i} \beta\right)}{P\left(y_{i}=0 \vee x_{i} \beta\right)}\right)=x_{i} \beta
$$

A Equação (6) é utilizada, no caso de dados agrupados, para estimação de regressões logísticas por mínimos quadrados ponderados. Outra possibilidade, mesmo com dados agrupados, é estimar o modelo logit por máxima verossimilhança. A função de verossimilhança, para o caso de dados individuais é dada por:

$$
\begin{aligned}
& V=\prod_{y_{i}=1} P\left(y_{i}=1 \vee x_{i}^{\prime} \beta\right) \prod_{y_{i}=0} P\left(y_{i}=0 \vee x_{i}^{\prime} \beta\right) \\
= & \prod_{y_{i}=1} P\left(y_{i}=1 \vee x_{i}^{\prime} \beta\right) \prod_{y_{i}=0}\left[1-P\left(y_{i}=1 \vee x_{i}^{\prime} \beta\right)\right]
\end{aligned}
$$


Quando são utilizados dados agrupados, os indivíduos são aglomerados em grupos, dentro dos quais são indistinguíveis, porque não há informações individuais. Assim para alguns indivíduos $i$ e $j$, todos os regressores serão iguais, e a função de verossimilhança assume a seguinte forma:

$$
V=\prod_{m} P\left(y_{i}=1 \vee x_{m}^{\prime} \beta\right)^{m_{1}} P\left(y_{i}=0 \vee x_{m} \beta\right)^{m_{0}}
$$

pela simples junção dos termos multiplicativos idênticos em potências, em que $m$ é o índice para os municípios, $m_{1}$ é a quantidade de sucessos e $m_{0}$ a quantidade de fracassos no município $m$. No caso em análise, $m_{1}=P_{I} \times$ (quantidade de famílias elegíveis no município).

Ocorre que, em nosso entendimento, quando se utiliza máxima verossimilhança na estimação de uma regressão com dados agrupados, não há diferença substancial de método decorrente da utilização de dados agrupados ou individuais. A metodologia adotada é essencialmente a mesma. Quando se opta por utilizar mínimos quadrados, entende-se que surge uma diferença substancial, porque essa última metodologia não se aplica a microdados, a menos que sejam agrupados para esse fim.

A variável dependente $y_{i}$ é estimada a partir de dados agrupados. Assim, são abstraídas as diferenças de probabilidade de seleção entre as diversas famílias elegíveis em um mesmo município, e as probabilidades estimadas passam representar as coberturas estimadas do PBF nos municípios.

\subsection{Descrição dos Regressores}

As variáveis explicativas consideradas para efeito de investigação sobre a determinação da probabilidade de cobertura do PBF nos municípios brasileiros se classificam em três grupos: variáveis socioeconômicas (PIB per capita, Coeficiente de Gini e Taxa de Analfabetismo), variáveis institucionais (IGDM, Receita Tributária per capita e razão beneficiários/elegíveis), variáveis de modernização e de infraestrutura (densidade demográfica, taxa de domicílios com eletricidade, razão escolas/crianças e taxa de domicílios abastecidos com água da rede pública).

As variáveis PIB per capita, Densidade Demográfica e Receita Tributária per capita representam o grau de desenvolvimento econômico, tamanho e a capacidade de arrecadação dos municípios, respectivamente. Um sinal positivo dos parâmetros estimados indicam que uma maior cobertura do PBF estaria associada a municípios mais populosos e com maior nível de renda per capita, os quais possuem melhor estrutura administrativa pública, servidores públicos mais qualificados e melhor desempenho da fiscalização tributária, características que permitem maiores chances de se selecionar corretamente as famílias com perfil de alta vulnerabilidade social. Por sua vez, um sinal negativo dos parâmetros estimados fornecem evidências em favor de uma maior probabilidade de cobertura do PBF em municípios menos povoados, com menores níveis de renda per capita e de arrecadação tributária per capita e que, geralmente, se tratam de municípios dependentes de transferências governamentais, e onde reside uma parcela significativa do público-alvo do PBF.

As variáveis Taxa de Domićlios com Eletricidade e Taxa de Domicílios com Água Abastecida pela Rede Pública referem-se, respectivamente, à proporção de domícílios particulares que possuem energia elétrica (segundo Tabela 1395 do Censo Demográfico 2010) e abastecimento de água proveniente 
de uma rede geral de abastecimento, pelo total de domicílios do município, em termos percentuais. Um sinal positivo dos parâmetros estimados indica que, em municípios onde se observa uma maior presença do Estado, há uma melhor capacidade de gestão dos recursos do PBF, resultando em uma maior cobertura do programa. Por sua vez, um sinal negativo dos parâmetros estimados evidenciaria que, em municípios mais pobres e/ou rurais, onde há uma maior probabilidade de possuírem baixas taxas de cobertura da rede elétrica e carência no fornecimento de água pela rede pública, a cobertura do PBF seria maior, cumprindo assim seu papel de programa de inclusão social.

O Coeficiente de Gini é uma medida do grau de desigualdade de renda existente na distribuição de indivíduos segundo a renda domiciliar per capita. Seu valor varia de 0 , quando não há desigualdade (a renda domiciliar per capita de todos os indivíduos tem o mesmo valor), a 1, quando a desigualdade é máxima (apenas um indivíduo detém toda a renda). O universo de indivíduos é limitado àqueles que vivem em domicílios particulares permanentes. Maiores medidas de Gini (isto é, sinal positivo do parâmetro estimado) proporcionariam menores dificuldades de gestão dos recursos do PBF nesses municípios, uma vez que a identificação da população mais pobre seria realizada de maneira mais fácil. Por outro lado, medidas de Gini menores (isto é, sinal negativo do parâmetro estimado) seriam relacionadas a maiores dificuldades de identificação dos elegíveis ao programa. Portanto, o Coeficiente de Gini tende a estar positivamente correlacionado com a probabilidade de cobertura do PBF.

A Taxa de Analfabetismo corresponde ao percentual de pessoas com 15 anos ou mais de idade que não sabem ler e escrever pelo menos um bilhete simples, no idioma que conhecem, na população total residente da mesma faixa etária, em determinado espaço geográfico, no ano considerado. Um sinal negativo no parâmetro estimado pode indicar que, em municípios onde a taxa de analfabetismo seja menor, seus habitantes mais pobres seriam mais conscientes e propensos à reivindicação. De outra forma, um sinal positivo do parâmetro estimado nos leva a aferir sobre uma associação positiva entre a probabilidade de cobertura do PBF e o insuficiente padrão educacional municipal. Vale ressaltar que a própria taxa de analfabetismo costuma estar associada ao grau de desenvolvimento econômico local.

A razão escolas/crianças refere-se ao número de escolas públicas que oferecem educação básica relativamente ao total de crianças com idade entre 0 a 17 anos. Trata-se de uma variável proxy de oferta de escolas, e busca-se vincular a maior oferta de escolas à contrapartida exigida no PBF de que as crianças das famílias deveriam frequentar no mínimo $85 \%$ das aulas. Nesse contexto, uma interpretação possível seria a de que uma maior medida de escolas/crianças refletiria uma maior oferta de escolas nos municípios. Se a oferta de escolas nos municípios for restrita a ponto de desencorajar as famílias a enviarem suas crianças às escolas, isso impediria essas famílias, ainda que elegíveis a serem beneficiárias do PBF. Logo, uma oferta maior de escolas nos municípios agiria como um facilitador para as famílias se interessarem em participar do programa, uma vez que desse modo poderiam cumprir suas contrapartidas.

O Índice de Gestão Descentralizada Municipal (IGD-M), que é um indicador que varia de 0 a 1 , avalia a qualidade e a atualização das informações do Cadastro Único por parte da gestão municipal, assim como a qualidade e a integridade das informações sobre o cumprimento das condicionalidades das áreas de Educação e de Saúde. Possui periodicidade anual, e no seu cálculo 
leva-se em consideração a multiplicação de quatro fatores: fator de operação do PBF, fator de adesão ao Sistema Único de Assistência Social (SUAS), fator de informação da apresentação da comprovação de gastos dos recursos do IGD-M, e fator de informação de aprovação total da comprovação de gastos dos recursos do IGD-M pelo Conselho Municipal de Assistência Social ${ }^{4}$. De acordo com Araújo et al. (2015), o principal componente do IGD-M é o fator de operação, que trata de variáveis sínteses dos processos restritos à gestão municipal do programa, sendo este formado por quatro subindicadores: cobertura do Cadastro Único, atualização do Cadastro Único, condicionalidade da Educação e condicionalidade da Saúde. Por exemplo, a cobertura do Cadastro Único trata do número de inscritos no cadastro do PBF com perfil de renda per capita em situação de pobreza e pobreza extrema no município, em conformidade com os dados censitários do IBGE. Já a atualização do cadastro, que é um mecanismo adotado para que o PBF mantenha a focalização ao longo do tempo, consiste em verificar se as famílias que recebem o benefício permanecem sob a condição de pobreza, permitindo sua participação no PBF, sendo feita a cada dois anos por agentes municipais que revisitam as famílias para verificarem se as condições de vida mudaram ou permaneceram as mesmas.

A condicionalidade da educação objetiva que todas as crianças e adolescentes entre 6 e 17 anos devem estar devidamente matriculadas e com frequência escolar mensal mínima ( 6 a 15 anos: 85\% da carga horária; 16 e 17 anos: $75 \%$ da carga horária, no mínimo). Por sua vez, a condicionalidade da saúde tem por objetivo idas semestrais aos estabelecimentos de saúde onde as famílias devem ser acompanhadas quanto à imunização das crianças, acompanhamento pré-natal das gestantes, assim como deve ser realizada antropometria (mensuração de peso e altura/comprimento) para monitoramento do estado nutricional dos indivíduos, verificando em que dimensão a insegurança alimentar grave está sendo combatida (Araújo et al. 2015).

Criado pela Portaria MDS/GM n ${ }^{\circ} 148 / 2006$ e alterado pela Portaria MDS /GM no 754/2010, o IGD-M tem como objetivo avaliar mensalmente a qualidade da gestão do Programa Bolsa Família em cada município e, a partir dos resultados indicados, oferecer apoio para que os municípios melhorem suas respectivas gestões. Com base nesse indicador, o MDS repassa recursos aos municípios para incentivar o aprimoramento da qualidade da gestão do Programa Bolsa Família, em âmbito local, e contribui para que os municípios executem as ações que estão sob sua responsabilidade. Quanto maior o valor do IGD-M, maior será também o valor dos recursos a serem repassados. Esperase que o parâmetro estimado referente a essa variável tenha sinal positivo, já que o IGD-M deve refletir, entre outros fatores, a qualidade da gestão do Cadastro Único no município e estaria associado, portanto, a um vazamento menor.

A proporção de famílias beneficiárias sobre famílias elegíveis $\frac{B}{E}$ retrata o aporte relativo de recursos do programa ao município, e espera-se um sinal positivo para o parâmetro correspondente, pois, como essa variável influencia a probabilidade de cobertura diretamente, haja vista a identidade apresentada na Equação (2), quanto maior o aporte relativo de recursos a um município, maior o alcance para um mesmo vazamento. Os demais regressores influen-

\footnotetext{
${ }^{4}$ Os três últimos fatores, quando cumpridos, apenas multiplicam o Fator I por 1, de modo que o Fator de Operação é o componente principal do IGD-M. Maiores informações sobre a metodologia de cálculo do IGD-M encontram-se disponíveis em: http: / / www . mds.gov.br / bolsafamilia/gestaodescentralizada/CadernodoIGD-M
} 
ciam a variável dependente indiretamente por meio da influência sobre o vazamento.

No que se refere à estimação econométrica do modelo logit, as informações sobre as variáveis PIB, população municipal, Taxa de Domicílios com Eletricidade e Taxa de Domicílios com Água Abastecida pela Rede Pública foram obtidas no sítio eletrônico do IBGE ${ }^{5}$.

A variável Densidade Demográfica, que é dada pela razão população total e a área do município (hab $/ \mathrm{km}^{2}$ ) para o ano de 2010 , foi construída a partir das informações sobre população de residente em áreas urbanas e área do município, sendo obtidas no sítio eletrônico do IPEADATA ${ }^{6}$.

Os dados sobre o IGD-M foram obtidos junto ao MDS ${ }^{7}$. Já as informações sobre a variável Receita Tributária foram obtidas no banco de dados "Finanças do Brasil: Dados Contábeis dos Municípios (FINBRA)" para o ano de 2010, disponibilizado no sítio eletrônico da Secretaria do Tesouro Nacional (STN) ${ }^{8}$. Em particular, no tocante ao Distrito Federal (DF), recorreu-se às informações constantes no arquivo de Execução Orçamentária dos Estados, disponível no sítio eletrônico da STN.

As informações sobre a variável Taxa de Analfabetismo foram obtidas no sítio eletrônico do DATASUS ${ }^{9}$. O Coeficiente de Gini foi estimado a partir dos microdados da amostra do Censo 2010 (IBGE), e da aproximação da renda familiar ajustada per capita ex-ante, descrita no Apêndice deste estudo. A variável beneficiários/elegíveis também foi construída a partir dos microdados da amostra do Censo IBGE 2010. Por fim, a variável escolas/crianças foi construída a partir de informações constantes no sítio do IBGE e no Instituto Nacional de Estudos e Pesquisas Educacionais Anísio Teixeira (INEP).

A Tabela 3 a seguir apresenta os resultados das principais estatísticas descritivas das variáveis utilizadas nesse estudo. Observa-se que, em média, 97\% dos municípios apresentam domicílios que possuem energia elétrica, e que $69 \%$ dos municípios apresentam domicílios com água abastecida pela rede pública. Apesar de que, em média, o PIB per capita é de $\mathrm{R} \$ 12.786,75$, a Receita Tributária per capita é de $\mathrm{R} \$ 122,95$, e a densidade demográfica é de 108,19 habitantes por $\mathrm{km}^{2}$, deve-se levar em consideração a dispersão dos dados conforme valores dos respectivos desvios-padrão, e pelos valores de máximo e de mínimo. Em média, tratam-se de municípios muito heterogêneos em relação à desigualdade de renda, conforme pode ser visto nos valores mínimo e máximo do Coeficiente de Gini, os quais demonstram uma alta dispersão. Entretanto, tratam-se de municípios que apresentam uma boa gestão dos recursos do Programa Bolsa Família, conforme o valor médio de 0,805 do IGD-M. Observa-se uma maior dispersão dos dados relacionados às variáveis taxa de analfabetismo e relação Escolas/Crianças. Já a relação Beneficiário/Elegível apresenta baixos valores de média e de desvio-padrão.

Para o Brasil, a cobertura do PBF $\left(P_{I}\right)$ é, em média, 0,61, com um baixo desvio-padrão. Ao se realizar uma análise segmentada da probabilidade de cobertura do PBF por tercis para fins de comparação de médias, observa-se o

\footnotetext{
${ }^{5}$ Informação disponível em http://www.ibge.gov.br/home/download/ estatistica.shtm.

${ }^{6}$ Informação disponível em http: / / www . ipeadata . gov .br.

${ }^{7}$ Informação disponível em http : / / www . mds . gov. br / bolsafamilia.

${ }^{8}$ Informações disponíveis em http://www.tesouro.fazenda.gov.br/ estados_municipios/index.asp.

${ }^{9}$ Informações disponíveis em ht tp : / / www. datasus .gov.br.
} 
Tabela 3: Estatísticas descritivas

\begin{tabular}{lrrrrr}
\hline Variável & Obs. & Média & Desvio-Padrão & Mínimo & Máximo \\
\hline$P_{I}$ & 5564,00 & 0,610 & 0,189 & 0,000 & 1,000 \\
PIB per capita & 5564,00 & 12786,750 & 14142,890 & 2269,820 & 296884,700 \\
Gini & 5564,00 & 0,500 & 0,069 & 0,290 & 0,854 \\
Taxa de Analfabetismo & 5564,00 & 15,810 & 9,750 & 0,900 & 47,100 \\
IGD-M & 5564,00 & 0,805 & 0,087 & 0,473 & 0,978 \\
Receita Tributária per capita & 5564,00 & 122,950 & 178,310 & 0,000 & 3739,340 \\
Beneficiários/Elegíveis & 5564,00 & 1,528 & 0,826 & 0,000 & 14,750 \\
Densidade Demográfica & 5564,00 & 108,190 & 572,410 & 0,130 & 13049,890 \\
Taxa de Domicílios com Eletricidade & 5564,00 & 97,040 & 5,800 & 29,220 & 100,000 \\
Escolas/Crianças & 5564,00 & 0,005 & 0,003 & 0,001 & 0,038 \\
Taxa de Domić́lios com Água RP & 5564,00 & 69,097 & 19,934 & 0,000 & 99,960 \\
\hline$P_{I}(1$ Tercil) & 1855,00 & 0,387 & 0,118 & 0,000 & 0,541 \\
$P_{I}$ (2 Tercil) & 1855,00 & 0,639 & 0,054 & 0,541 & 0,728 \\
$P_{I}$ (3 Tercil) & 1854,00 & 0,803 & 0,048 & 0,728 & 1,000 \\
\hline Nota: Elabo
\end{tabular}

Nota: Elaboração dos autores. "RP" significa Rede Pública. No conjunto de 11 variáveis para 5.564 municípios (unidades cross-section), a quantidade de informações totaliza 267.072.

1 - O 1 tercil representa o grupo de municípios com menor quantidade de famílias elegíveis; O 3 tercil representa grupo de municípios com maior quantidade de famílias elegíveis; $\mathrm{O} 2$ tercil representa o grupo intermediário de municípios com famílias elegíveis.

2 - No que se refere à variável "taxa de domicílios abastecidos com água da rede pública”, obtida no DATASUS, o valor zero corresponde aos valores ausentes (missing values) correspondentes aos seguintes cinco municípios: (i) Betânia do Piauí/PI (código IBGE n 2201739); (ii) Santa Cecília/PB (código IBGE n 2513158); (iii) Santo André/PB (código IBGE n 2513851); (iv) São José do Brejo do Cruz/PB (código IBGE n 2514651); (v) Sossego/PB (código IBGE n 2516151).

O valor mínimo zero para a variável beneficiários/elegíveis se refere ao município Monte Belo do Sul/Rio Grande do Sul (código IBGE n 4312385) que, após a aplicação do algoritmo (ver apêndice), obteve-se $\tilde{P}_{I}=0$ e $\tilde{N P}_{I}=0$, de modo que $B=\tilde{P}_{I}+N \tilde{P P}_{I}=0$, ou seja, não se obteve informações sobre famílias incluídas no programa nesse município. As razões podem ser as seguintes: (i) alguns beneficiários entrevistados pelo Censo podem ter respondido que não recebem o recurso. O próprio IBGE admite que a discrepância entre a estimativa do total dos declarantes beneficiários e a informação prestada pelo MDS é grande demais para representar um erro de estimativa. Muitos beneficiários devem ter negado na entrevista ao Censo. Além disso, a subdeclaração é um fenômeno universal em se tratando de programas de transferência de renda condicionada; (ii) alguns beneficiários entrevistados podem ter respondido ignorar se são, ou não, beneficiário e, nesse caso, o algoritmo atribui a condição de não beneficiário; (iii) alguns beneficiários entrevistados podem ter declarado serem beneficiários, mas ignorarem o valor da renda de outras fontes; (iv) alguns beneficiários entrevistados podem ter declarado serem beneficiários, terem informado os valores das rendas de outras fontes, mas terem caído em alguns dos filtros constantes no algoritmo, recebendo assim o status de não beneficiário, por exemplo, valor declarado de um salário mínimo para o benefício ou qualquer valor maior ou igual a dois salários mínimos. 
maior valor médio se concentra no $3^{\circ}$ tercil $(0,803)$, que representa o grupo de municípios com mais famílias elegíveis.

\section{Análise dos Resultados}

\subsection{Resultados Econométricos}

Antes de iniciar a estimação econométrica, houve a necessidade de se verificar a presença de multicolinearidade por meio de dois testes: (i) Fator de Inflação da Variância (VIF); e (ii) Conditional Index. VIF maior do que 10 e Conditional Index acima de 30 indicam presença de multicolinearidade.

Os resultados reportados na Tabela 4 a seguir indicam ausência de multicolinearidade entre as variáveis a serem utilizadas na estimação logit.

Tabela 4: Diagnóstico de multicolinearidade

\begin{tabular}{lcc}
\hline Variável & VIF & Cond. Index \\
\hline PIB per capita & 1,45 & 1,00 \\
Gini & 1,48 & 1,54 \\
Taxa de Analfabetismo & 2,29 & 1,79 \\
IGD-M & 1,65 & 1,98 \\
Densidade Demográfica & 1,10 & 2,06 \\
Taxa de Domićlios com Eletricidade & 1,47 & 2,20 \\
Escolas/Crianças & 1,42 & 2,42 \\
Taxa de Domićlios com Água RP & 1,36 & 2,58 \\
Receita Tributária per capita & 1,45 & 2,78 \\
Beneficiários/Elegíveis & 1,27 & 3,23 \\
\hline
\end{tabular}

Nota: Elaboração dos autores. "RP" significa Rede Pública.

Conforme destacado por Greene (2012) (p.729-730), os coeficientes estimados em uma regressão logística não representam diretamente as respostas marginais das variáveis explicativas como no método dos mínimos quadrados ordinários. Assim, foram utilizados os valores médios das variáveis explicativas para efetuar os cálculos dos efeitos marginais sobre a variável dependente $\operatorname{Prob}(y=1 \mid x)$, para cada uma das $k$ variáveis explicativas, em termos de elasticidades, da seguinte forma:

$$
\varepsilon_{j}=\frac{\partial(\operatorname{Prob}(y=1 \mid x=\dot{x}))}{\partial x_{j}} \times \frac{x_{j}}{\operatorname{Prob} \widehat{(y=1 \mid x}=\dot{x})}
$$

Em que $\partial\left(\operatorname{Prob}(y=1 \mid x=x) / \partial x_{j}=F(x \hat{x})[1-F(x \hat{x})] \hat{\beta}_{j}\right.$. A elasticidade $\varepsilon_{j}$ representa a mudança percentual da $\operatorname{Prob}(y=1 \mid x)$ decorrente do aumento de um por cento na $j$-ésima variável explicativa, com todos os regressores avaliados em seus valores médios. As estimativas dessas elasticidades relacionadas ao modelo logit para dados agrupados, tanto para o Brasil, quanto por macrorregiões, são apresentadas na Tabela 5. Por exemplo, no caso do modelo logit para o Brasil, o aumento de $1 \%$ no PIB per capita reduz em $0,024 \%$ a probabilidade de cobertura do PBF.

Em relação à situação socioeconômica dos municípios, os sinais negativos das elasticidade-renda, elasticidade-receita tributária e elasticidade-densidade demográfica corroboram as evidências de que a probabilidade de cobertura do PBF é maior, na média, em municípios com menores PIB per capita, Receita 
Tabela 5: Efeitos marginais do modelo logit para dados agrupados. Variável dependente: probabilidade de cobertura do $\operatorname{PBF}\left(P_{I}\right)$

\begin{tabular}{|c|c|c|c|c|c|c|}
\hline Variáveis & $\begin{array}{l}\text { Brasil } \\
\quad \varepsilon_{j}\end{array}$ & $\begin{array}{l}\text { Norte } \\
\varepsilon_{j}\end{array}$ & $\begin{array}{c}\text { Nordeste } \\
\varepsilon_{j}\end{array}$ & $\begin{array}{c}\text { Sudeste } \\
\varepsilon_{j}\end{array}$ & $\begin{array}{c}\text { Sul } \\
\varepsilon_{j}\end{array}$ & $\begin{array}{c}\text { Centro-Oeste } \\
\varepsilon_{j}\end{array}$ \\
\hline PIB per capita & $\begin{array}{l}-0,024 \\
(0,000)^{* * *}\end{array}$ & $\begin{array}{l}-0,024 \\
(0,001)^{* * * *}\end{array}$ & $\begin{array}{l}-0,001 \\
(0,000)^{* * * *}\end{array}$ & $\begin{array}{l}-0,021 \\
(0,000)^{* * *}\end{array}$ & $\begin{array}{l}-0,011 \\
(0,001)^{* * *}\end{array}$ & $\begin{array}{l}-0,091 \\
(0,002)^{* * *}\end{array}$ \\
\hline Gini & $\begin{array}{c}0,212 \\
(0,001)^{* * * *}\end{array}$ & $\begin{array}{c}0,211 \\
(0,004)^{* * *}\end{array}$ & $\begin{array}{c}0,163 \\
(0,001)^{* * *}\end{array}$ & $\begin{array}{c}0,113 \\
(0,003)^{* * *}\end{array}$ & $\begin{array}{c}0,858 \\
(0,007)^{* * *}\end{array}$ & $\begin{array}{c}0,395 \\
(0,009)^{* * *}\end{array}$ \\
\hline Taxa de Analfabetismo & $\begin{array}{c}0,154 \\
(0,000)^{* * *}\end{array}$ & $\begin{array}{c}0,073 \\
(0,001)^{* * *}\end{array}$ & $\begin{array}{c}0,186 \\
(0,001)^{* * *}\end{array}$ & $\begin{array}{c}0,203 \\
(0,001)^{* * *}\end{array}$ & $\begin{array}{c}0,162 \\
(0,002)^{* * *}\end{array}$ & $\begin{array}{c}0,267 \\
(0,004)^{* * *}\end{array}$ \\
\hline IGD-M & $\begin{array}{c}0,666 \\
(0,002)^{* * *}\end{array}$ & $\begin{array}{c}0,835 \\
(0,004)^{* * *}\end{array}$ & $\begin{array}{c}0,382 \\
(0,002)^{* * *}\end{array}$ & $\begin{array}{c}0,762 \\
(0,004)^{* * *}\end{array}$ & $\begin{array}{c}0,289 \\
(0,007)^{* * *}\end{array}$ & $\begin{array}{c}0,339 \\
(0,011)^{* * *}\end{array}$ \\
\hline Receita Tributária per capita & $\begin{array}{c}0,008 \\
(0,000)^{* * *}\end{array}$ & $\begin{array}{c}0,029 \\
(0,000)^{* * *}\end{array}$ & $\begin{array}{c}0,005 \\
(0,000)^{* * *}\end{array}$ & $\begin{array}{c}0,029 \\
(0,000)^{* * *}\end{array}$ & $\begin{array}{c}0,065 \\
(0,001)^{* * * *}\end{array}$ & $\begin{array}{c}0,004 \\
(0,000)^{* * * *}\end{array}$ \\
\hline Razão Beneficiários/Elegíveis & $\begin{array}{c}0,365 \\
(0,001)^{* * *}\end{array}$ & $\begin{array}{c}0,530 \\
(0,002)^{* * *}\end{array}$ & $\begin{array}{c}0,302 \\
(0,001)^{* * *}\end{array}$ & $\begin{array}{c}0,349 \\
(0,002)^{* * *}\end{array}$ & $\begin{array}{c}0,434 \\
(0,003)^{* * *}\end{array}$ & $\begin{array}{c}0,383 \\
(0,004)^{* * *}\end{array}$ \\
\hline Densidade Demográfica & $\begin{array}{l}-0,001 \\
(0,000)^{* * * *}\end{array}$ & $\begin{array}{l}-0,001 \\
(0,000)^{* * *}\end{array}$ & $\begin{array}{l}-0,001 \\
(0,000)^{* * * *}\end{array}$ & $\begin{array}{l}-0,001 \\
(0,000)^{* * *}\end{array}$ & $\begin{array}{l}-0,002 \\
(0,000)^{* * * *}\end{array}$ & $\begin{array}{l}-0,004 \\
(0,000)^{* * * *}\end{array}$ \\
\hline Taxa de Domicílios com Eletricidade & $\begin{array}{c}0,100 \\
(0,003)^{* * *}\end{array}$ & $\begin{array}{l}-0,104 \\
(0,005)^{* * *}\end{array}$ & $\begin{array}{l}-0,060 \\
(0,003)^{* * *}\end{array}$ & $\begin{array}{l}-1,511 \\
(0,033)^{* * *}\end{array}$ & $\begin{array}{l}-4,110 \\
(0,078)^{* * *}\end{array}$ & $\begin{array}{l}-0,624 \\
(0,022)^{* * *}\end{array}$ \\
\hline Razão Escolas/Crianças & $\begin{array}{c}0,046 \\
(0,000)^{* * *}\end{array}$ & $\begin{array}{c}0,057 \\
(0,001)^{* * *}\end{array}$ & $\begin{array}{c}0,039 \\
(0,000)^{* * *}\end{array}$ & $\begin{array}{c}0,037 \\
(0,001)^{* * *}\end{array}$ & $\begin{array}{c}0,062 \\
(0,002)^{* * *}\end{array}$ & $\begin{array}{l}-0,031 \\
(0,003)^{* * *}\end{array}$ \\
\hline Taxa de Domicílios com Água Abastecida pela Rede Pública & $\begin{array}{l}-0,040 \\
(0,001)^{* * *}\end{array}$ & $\begin{array}{c}0,002 \\
(0,001)^{* *}\end{array}$ & $\begin{array}{l}-0,021 \\
(0,001)^{* * *}\end{array}$ & $\begin{array}{l}-0,085 \\
(0,002)^{* * *}\end{array}$ & $\begin{array}{l}-0,040 \\
(0,004)^{* * *}\end{array}$ & $\begin{array}{l}-0,028 \\
(0,004)^{* * *}\end{array}$ \\
\hline Teste de Wald & $\begin{array}{c}4690409,05 \\
{[0,000]^{* * * *}}\end{array}$ & $\begin{array}{c}246424,59 \\
{[0,000]^{* * *}}\end{array}$ & $\begin{array}{c}918066,35 \\
{[0,000]^{* * *}}\end{array}$ & $\begin{array}{c}1136303,99 \\
{[0,000]^{* * *}}\end{array}$ & $\begin{array}{c}149759,66 \\
{[0,000]^{* * *}}\end{array}$ & $\begin{array}{c}73560,88 \\
{[0,000]^{* * *}}\end{array}$ \\
\hline Pseudo- $\mathrm{R}^{2}$ de McFadden & 0,1187 & 0,0388 & 0,0443 & 0,1222 & 0,0565 & 0,0363 \\
\hline Número de Observações & 5564 & 449 & 1793 & 1668 & 1188 & 466 \\
\hline
\end{tabular}

Nota: Elaboração dos autores. Estimações econométricas realizadas no Software Econométrico Stata/SE, versão 12, considerando-se o seguinte:

1 - Erros-padrão robustos entre parênteses, p-valor entre colchetes. $\left.{ }^{*}\right)$ significância a $1 \%(p<0,01) ;\left({ }^{* *}\right)$ significância a $5 \%(p<0,05)$; $\left({ }^{* * *}\right)$

significância a $10 \%(p<0,1)$. Em relação aos efeitos marginais condicionados, no cálculo das elasticidades utilizou-se o comando "margins, eyex $\left(^{*}\right)$ atmean noatlegend". Fonte: Cameron \& Trived (2010) (p. 351). Como os modelos de resposta binária são, essencialmente, heterocedásticos, tornando os desvios-padrão estimados viesados, utilizou-se para a estimação da matriz de variância e covariância dos resíduos, desvios-padrão robustos à heterocedasticidade (entre parênteses), conforme proposto por White (1980), com o uso da opcão "vce (robust)". No modelo logit para o Brasil, considera-se a presença de constante e de variáveis dummies por macrorregiões (mas a variável dummy para a região Sudeste foi omitida pelo Stata devido à colinearidade).

4 - O pseudo- $\mathrm{R}^{2}$ de McFadden é um indicador sintético de qualidade do ajustamento da estimação similar ao coeficiente de determinação $\mathrm{R}^{2}$ da regressão linear por mínimos quadrados ordinários (McFadden et al. 1973), sendo definido por: $1-L L F_{u r} / L F F_{r}$, em que $L L F_{u r}$ é a função logarítmica não restrita de verossimilhança na qual estão incluídos todos os regressores do modelo (isto é, equivale à soma dos quadrados dos resíduos), e $L L F_{r}$ é a função logarítmica restrita de verossimilhança na qual está incluído apenas o intercepto (isto é, equivale à soma dos quadrados totais). Seu valor encontra-se no intervalo 0 a 1 (Gujarati 2011) (p.560). Apesar de os resultados do pseudo- $\mathrm{R}^{2}$ apresentarem valores baixos na Tabela 5, em modelos logit, a qualidade do ajuste não é tão importante quanto a significância econômica e estatística das variáveis explicativas (Wooldridge 2002 , Hu et al. 2006). 
Tributária per capita e população. No que se refere à renda per capita, esse resultado confirma as evidências obtidas por Silveira Neto (2010) (p. 62) de que um maior nível de renda per capita diminui as chances de uma família ser beneficiada com recursos do PBF. Há de se investigar, entretanto, a diferença de magnitude da elasticidade-renda entre as macrorregiões. Em particular, o coeficiente próximo de zero estimado para o Nordeste pode indicar que o efeito marginal do PIB per capita seja menor para níveis menores de renda, que é o caso do Nordeste. Além disso, em municípios onde há carência de fornecimento de água pela rede pública (usualmente muncípios pobres e onde reside boa parte do público-alvo), a probabilidade de cobertura do PBF é maior ${ }^{10}$.

Os sinais positivos da elasticidade-desigualdade de renda, e da elasticidade associada à taxa de analfabetismo, indicam que a probabilidade de cobertura do PBF é maior em municípios onde há uma maior desigualdade de renda e maior taxa de analfabetismo. Uma maior desigualdade (medida de Coeficiente Gini) estar associada a uma maior probabilidade de cobertura sugere que a heterogeneidade de renda pode tornar mais visível ao gestor público o verdadeiro público alvo. Curiosamente, o efeito marginal do Gini é maior na região Sul. Isso pode ser devido ao fato dos municípios da região Sul apresentarem menores níveis de desigualdade e o efeito marginal da desigualdade sobre a focalização ser decrescente.

Observa-se, também, que, em municípios onde se observa uma melhor qualidade na gestão dos recursos e das informações de famílias beneficiadas pelo PBF, assim como uma maior relação Beneficiários/Elegíveis, a probabilidade de cobertura do PBF é maior. Entretanto, em relação a esse último aspecto, é necessário esclarecer que esse resultado ocorre por construção, uma vez que a variável beneficiários/elegíveis retrata o aporte relativo de recursos do Programa Bolsa Família ao município, conforme visto anteriormente. Além disso, todos os resultados apresentados neste estudo devem ser interpretados via impacto sobre o vazamento.

Quando avaliado isoladamente o impacto da variável razão escolas/crianças, verificamos uma contribuição positiva sobre a probabilidade de cobertura do PBF, evidenciando que, quanto maior for a presença física do Estado, maior o alcance do PBF às famílias elegíveis, uma vez que a escola pode ser considerada um instrumento do Estado para alcançar os potenciais beneficiários do PBF.

\subsection{Simulação sob Perfeita Focalização do PBF}

Nesta seção, realiza-se uma simulação sob a hipótese de perfeita focalização, sendo definida como uma situação em que o vazamento é nulo (nenhum inelegível é incluído no programa) e ocorre a universalização do programa (todos os elegíveis são incluídos no programa). Nessa simulação, descrita na Figura 5 a seguir, considerou-se as famílias brasileiras organizadas em ordem crescente de renda familiar per capita ex-ante aproximada, e se distribuiu os benefícios do PBF nessa ordem. Além disso, a distribuição dos benefícios do Programa Bolsa Família é feita até que a renda da pessoa ultrapasse o valor da linha de pobreza.

\footnotetext{
${ }^{10}$ A região Centro-Oeste apresenta duas divergências de sinais dos coeficientes em relação às demais regiões. A primeira é o sinal positivo da receita tributária. A segunda é o sinal negativo da razão escolas/crianças. Essas correlações podem dever-se a fatores idiossincráticos da região e devem ser objetos de futuras investigações.
} 
Abstraindo-se as imprecisões das estimativas da renda das famílias, estimase que, se os gestores públicos tivessem acesso à informação perfeita (hipótese de perfeita focalização), seriam necessários $R \$ 8,7$ bilhões para universalizar o PBF em 2010. Além disso, o montante efetivamente gasto naquele ano pelo governo, R\$ 14,4 bilhões (Revista Brasileira de Monitoramento e Avaliação 2012) ${ }^{11}$, sob essa hipótese, permitiria a extensão do PBF a todas as famílias com renda per capita até $\mathrm{R} \$ 400,00$.

Todavia, essa simulação sob a hipótese de perfeita focalização deve ser ponderada para questões relacionadas ao custo de obtenção das informações necessárias. A identificação precisa do público-alvo exigiria: (i) uma ampla pesquisa de campo que estendesse o Cadastro Único ao ponto de incluir todas as famílias elegíveis; (ii) o correto registro da renda habitual das famílias cadastradas - vencendo inclusive o obstáculo da assimetria de informação inerente ao comportamento estratégico dos agentes; e, por fim, (iii) um monitoramento contínuo para identificação de famílias levadas à situação de pobreza pela oscilação de sua renda, bem como, por outro lado, daquelas que tenham logrado inserir-se no mercado de trabalho.

É óbvio que o esforço para levantamento de toda essa informação implicaria um custo elevado, mas sua estimativa foge ao escopo do presente estudo. De qualquer maneira, é importante assinalar que a existência de um custo não desprezível para identificação precisa do público alvo faz com que um determinado nível de vazamento seja aceitável. Assim, os resultados apresentados nessa simulação, sob hipótese restritiva, trazem importantes insights para fins de política econômica.

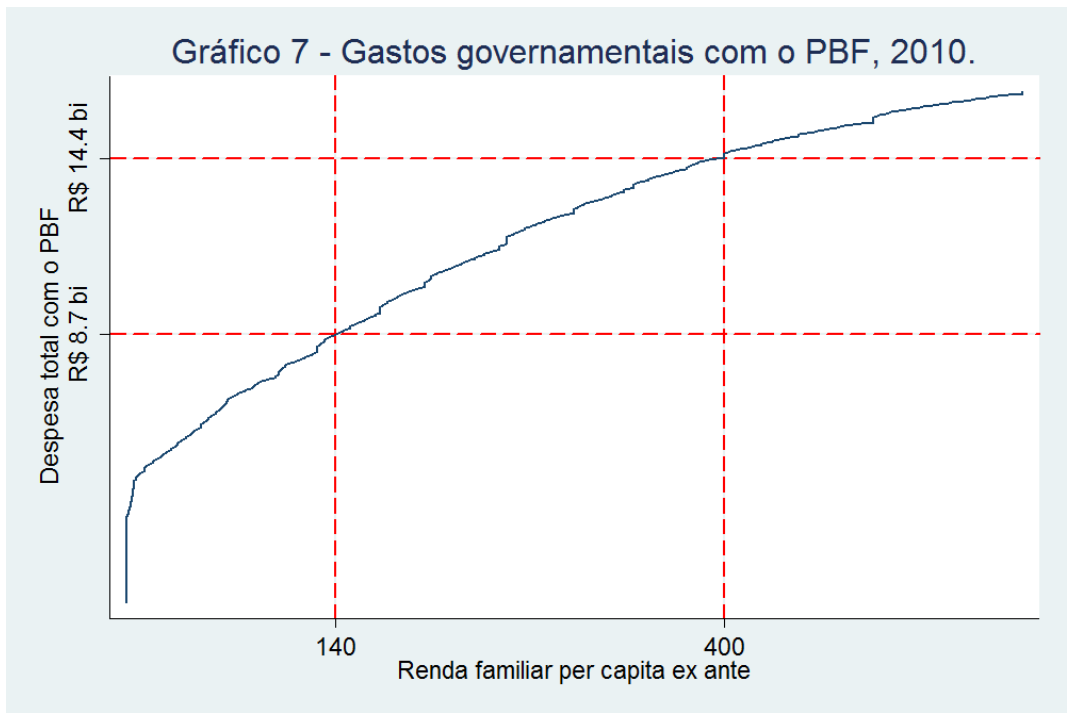

Nota: Elaboração dos autores.

Figura 5: Gastos governamentais com PBF, 2010

\footnotetext{
${ }^{11}$ Fonte: BRASIL. Revista Brasileira de Monitoramento e Avaliação, número 3. Gráfico 2: Gasto Total do Governo Federal com o PBF - Brasil 2004/2012 (página 80). Brasília, DF, Ministério do Desenvolvimento e Combate à Fome, Secretaria de Avaliação e Gestão da Informação, janjun/2012. Disponível em: http://aplicacoes.mds.gov.br/sagirmps/ferramentas/ docs/RBMAs/RBMA_03.pdf. Acesso em: 23 março 2015.
} 


\subsection{Simulações de Políticas}

Esta seção descreve os resultados de duas simulações, realizadas a partir dos resultados econométricos apresentados na seção anterior, com vistas a avaliar com mais detalhe o impacto do IGD-M, e depois da relação Benefícios/Elegíveis, sobre a cobertura nacional estimada para o PBF. Assim, consideram-se, para cada município, os seus dados originais, com exceção da variável de interesse (alternadamente, IGD-M e Benefícios/Elegíveis), que foi estabelecida a um mesmo nível para todos os municípios. Considerando vários níveis ao longo do escopo apresentado pela amostra, logrou-se descrever o comportamento da cobertura estimada do PBF e sua sensibilidade a variações das variáveis de interesse.

As Figuras 6 e 7 mostram, respectivamente, as coberturas ajustadas para cada um dos níveis considerados de IGD-M e da razão beneficiários/elegíveis. Nesse último caso, considerou-se ainda a situação em que todos os municípios tivessem IGD-M máximo (igual a 1).

As estimativas indicam uma forte relação entre a qualidade da gestão do cadastro municipal medida pelo IGD-M e a cobertura estimada para o programa. Comparando as estimativas apresentadas na Figura 6 àquelas dispostas na Tabela 3, conclui-se que a melhoria da gestão municipal do cadastro pode efetivamente levar a maior cobertura por meio da redução do vazamento (erro tipo II). É notável, entretanto, a distância entre a ampliação de cobertura alcançável com a melhoria do IGD-M e a universalização do PBF. Essa constatação parece apontar para a possibilidade de que o IGD-M não reflita com perfeição a "contaminação" dos cadastros municipais com famílias inelegíveis, o que está relacionado, por sua vez, à própria dificuldade de filtrar essa contaminação, haja vista os custos envolvidos já mencionados na Seção 5.2.

Com relação à razão beneficiários/elegíveis, ao introduzir a identidade descrita na Equação (2), explica-se que a cobertura do $\operatorname{PBF}\left(P_{I}\right)$ depende do aporte de recursos $(B / E)$ e do vazamento $\left(N P_{I}\right)$, e pondera-se que, sendo $B / E$ uma variável de política, a qual é exógena, considera-se que o canal de transmissão para os demais regressores seria o vazamento, desprezando-se $N_{E} / B$ por simplificação. Assim, ao se inserir $B / E$ como regressor, e alterar seu valor em uma simulação, considera-se as demais variáveis (que influenciam o vazamento) constantes.

No entanto, ao se introduzir mais recursos, aumentando B/E, selecionase famílias elegíveis e também não elegíveis, de maneira que sobem ambos PI e NPI. O crescimento do NPI reduz o impacto do aumento dos recursos sobre o B/E. Assim, rigorosamente, o vazamento não tem como permanecer constante, a menos que os novos benefícios se destinassem apenas a famílias elegíveis. O coeficiente estimado para $B / E$ representa o efeito líquido do aumento de recursos menos o erro de seleção. É preciso esclarecer que, apesar de os demais regressores alterarem a cobertura por meio do vazamento, este também é afetado por alterações do aporte de recursos.

Além disso, convém esclarecer que cada incremento considerado na simulação, da ordem de 0,5 (ver Figura 7), representa um acréscimo substancial de recursos, tendo em vista que as estimativas obtidas com os microdados do Censo 2010 indicam uma razão de 1,415 naquele momento. Dessa maneira, considerando todos os municípios com o mesmo aporte relativo de recursos como proporção do número de famílias elegíveis e o PBF como desenhado à época (valores de benefícios e demais regras), estima-se que seria necessá- 
rio um acréscimo vultoso de recursos para a realização de uma cobertura de 90\% das famílias elegíveis. É interessante notar que uma melhoria substancial e generalizada das gestões dos cadastros municipais, segundo medidas pelo IGD-M, permitirá uma economia importante de recursos para obtenção desse mesmo nível de cobertura.

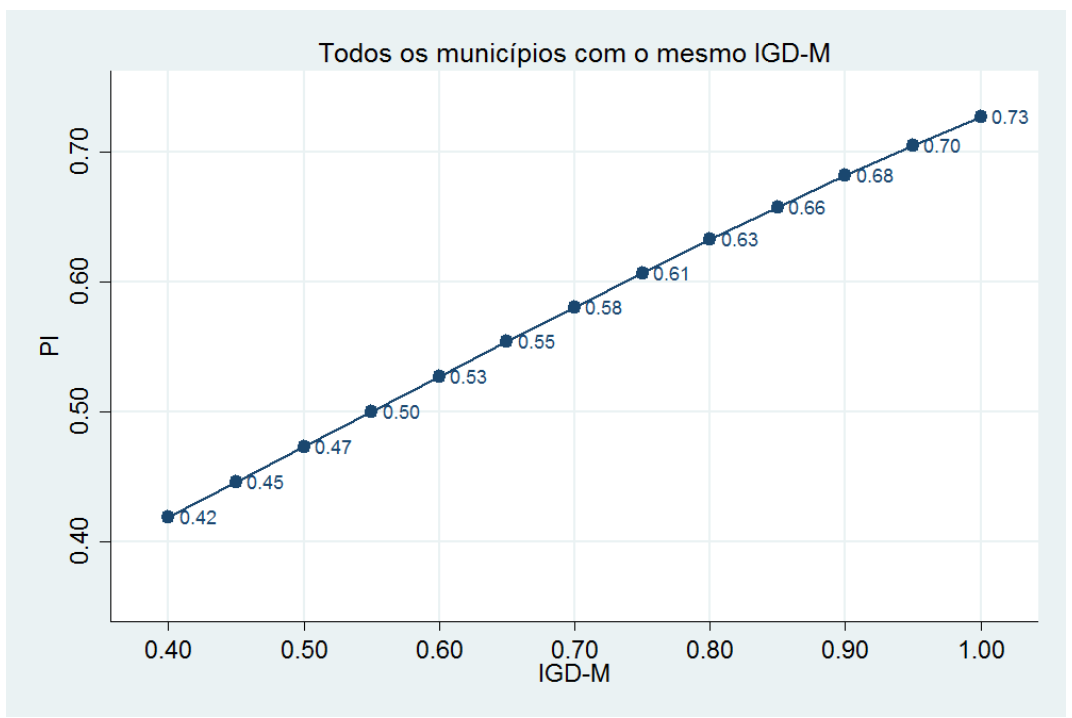

Nota: Elaboração dos autores.

Figura 6: Variações da qualidade de gestão dos cadastros segundo o IGD$\mathrm{M}$

Todavia, em relação à variável beneficiários/elegíveis, é importante explicar a diferença entre razão consistente com a simulação $(1,415)$ e a média aritmética reportada na Tabela 3 de estatística descritiva $(1,528)$. A simulação parte da hipótese de que há uma mesma relação beneficiários/elegíveis para todos os municípios, isto é, pressupõe uma hipotética redistribuição intermunicipal de recursos que resulta na relação beneficiários/elegíveis para todo o Brasil. Note que o denominador (famílias elegíveis) equivale a soma de PI e $\mathrm{PE}$, ao passo que numerador equivale ao número de famílias beneficiárias. Já a Tabela 3 de estatística descritiva faz o cálculo da média aritmética da variável beneficiários/elegíveis calculada para cada município. Finalmente, é importante informar que, nesse estudo, os dados ausentes (missing values) se referem à informação não declarada ${ }^{12}$.

\footnotetext{
${ }^{12}$ No presente estudo, os dados ausentes (missing values) se referem à informação não declarada, no nível individual, inicialmente. Por exemplo, são excluídas da amostra famílias cujos todos membros respondem "ignorar" se são, ou não, beneficiários. Após a aplicação dos filtros associados ao algoritmo descrito no apêndice deste estudo, e a correspondente agregação por município das informações tratadas, considerou-se como valor zero os dados ausentes em nível municipal, como se não estivesse faltando informação, de modo que os municípios que apresentavam dados ausentes sobre determinadas variáveis não foram excluídos da análise. Conforme reportado em nota de rodapé da Tabela 3, no conjunto de 11 variáveis para 5.564 municípios (unidades cross-section), a quantidade de informações totaliza 267.072. Constatou-se a existência de 173 missing values, distribuídos nas seguintes variáveis: inclusão correta ou cobertura (25), receita tributária per capita (142), razão beneficiários/elegíveis (1), e taxa de domicílios com abastecimento de água pela rede pública (5). Ou seja, tem-se uma taxa de 0,065\% de missing values,
} 


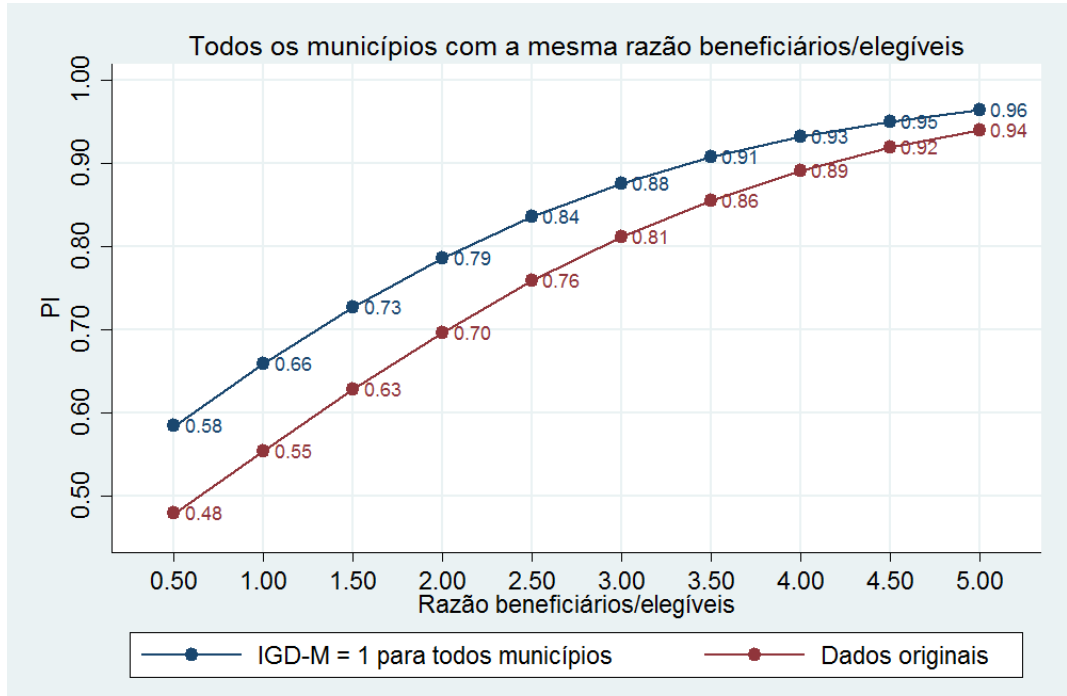

Nota: Elaboração dos autores.

Figura 7: Variações da relação benefíciários/elegíveis

\section{Considerações Finais}

A evidência empírica internacional tem mostrado que a descentralização de programas governamentais de redução de pobreza resulta em uma melhor focalização desses programas. Segundo argumenta Cavalcante (2011), as experiências conhecidas na América Latina, apesar de bem diversificadas, compartilham entre si três componentes básicos: transferência monetária direta à família, foco nos segmentos mais pobres e existência de condicionalidades. Outra similaridade comum a esses programas diz respeito à percepção de que a pobreza é um problema multidimensional e, portanto, o combate às precárias condições de vida da população tem caminhado em paralelo com iniciativas nas áreas de educação, saúde, habitação, assistência social e trabalho.

Um dos focos da descentralização de programas governamentais de redução de pobreza tem sido melhorar a accountability no processo de prestação do serviço público, limitando os problemas inerentes ao sistema centralizado tradicional. $\mathrm{O}$ argumento em favor de descentralizar o fornecimento do serviço público reside no fato de que os governos locais estarão sujeitos a pressões eleitorais dos cidadãos, os quais são mais capazes de monitorar a prestação do serviço público do que uma autoridade central distante (Bardhan \& Mookherjee 2005).

Este estudo teve por objetivo realizar uma investigação sobre a focalização do PBF e seus determinantes imediatos, assim como a realização de uma análise quantitativa sobre famílias beneficiárias, elegíveis e não elegíveis, utilizando-se as informações municipais constantes no Censo IBGE 2010 para implementação de um indicador de focalização baseado em medidas de alcance e de precisão do programa.

Um resultado interessante refere-se ao fato de que os percentuais associa-

não afetando a propriedade de eficiência do estimador, nem tornando os resultados aqui obtidos viesados. 
dos ao erro tipo I (exclusão indevida) são maiores que os percentuais associados ao erro tipo II (inclusão indevida). Além disso, quando observada a distribuição acumulada das famílias beneficiárias do PBF no ano de 2010, chega-se a uma estimativa de que $49,55 \%$ dessas famílias estariam recebendo acima do teto estabelecido em lei (até R\$140,00).

Contudo, conforme assinalado, parte da imprecisão está relacionada à inclusão de famílias com renda per capita acima, mas muito próxima do teto de $\mathrm{R} \$ 140,00$. Considerando uma natural oscilação da renda, é razoável relativizar a importância da inclusão indevida dessas famílias. Nesse sentido, seria de se esperar que esforços de redução do vazamento (erro tipo II) focassem na exclusão do programa de famílias beneficiárias com renda razoavelmente distante do teto estabelecido.

Os resultados econométricos do modelo logit estimado apontam para uma relação inversa entre a cobertura do programa e os níveis de desenvolvimento social e econômico dos municípios. Há evidências de que municípios com maior qualidade na gestão dos recursos do PBF, conforme mensurado pelo IGD-M, também apresentam percentuais superiores de cobertura. Sendo esta uma variável de gestão, é direto o bônus decorrente da adoção de boas práticas no gerenciamento do programa.

As simulações de política indicam uma forte relação entre a qualidade da gestão do cadastro municipal medida pelo IGD-M e a cobertura estimada para o programa. Entretanto, mesmo em uma simulação em que todos os municípios operam com IGD-M máximo, a probabilidade de cobertura atingida é de $73 \%$. Portanto, infere-se que um direcionamento de políticas para universalização do programa deve envolver esforços tanto para fins de efetivo alcance das famílias elegíveis, mas não beneficiárias, bem como para redução do vazamento do programa. Sem direcionar esforços nesses dois eixos, a universalização do programa requereria um aporte significativo de recursos.

Para pesquisas futuras, recomenda-se avaliar o atual desenho de mecanismos inerente aos índices de gestão descentralizada municipal e estadual (IGD-M e IGD-E), bem como sua importância como geradores de incentivos à melhor gestão dos recursos por parte dos entes subnacionais. Por fim, convém assinalar que, diante (i) da dificuldade de melhorar a precisão de um programa capilarisado como o PBF em país de dimensões continentais como o Brasil, e (ii) da grande parcela de famílias elegíveis ainda não incluídas no programa, é difícil imaginar sua universalização sem a expansão dos recursos destinados aos benefícios.

\section{Agradecimentos}

Os autores agradecem o excelente trabalho de assistente de pesquisa de Gabriel Weber Costa da Fundação Getúlio Vargas de São Paulo. Além disso, os autores agradecem ao parecerista anônimo da Revista Economia Aplicada, assim como aos participantes dos seguintes encontros, pelos comentários e sugestões de aprimoramentos: Seminário Regional de Política Fiscal da CEPAL (2013), VI Encontro CAEN-EPGE de Políticas Públicas e Crescimento Econômico (2013), 43º Encontro Nacional de Economia (2015), seminários acadêmicos da Universidade de Brasília e da Universidade Católica de Brasília. 


\section{Referências Bibliográficas}

Alatas, V., Banerjee, A., Hanna, R., Olken, B. A. \& Tobias, J. (2012), 'Targeting the poor: evidence from a field experimente in Indonesia', American Economic Review 102(2), 1206-1240.

Alderman, H. (2002), 'Do local officials know something we don't? Decentralization of targeted transfers in Albania', Journal of Public Economics 83(3), 375-404.

Anuatti-Neto, F., Fernandes, R. \& Pazello, E. (2001), Poverty alleviation policies: the problem of targeting when income is not observed. Ribeirão Preto, FEA/RP, 2001 (Texto para Discussão, n. 17).

Araújo, F. R., Araújo, M. A. D. \& Souza, F. J. (2015), 'Uma avaliação do índice de gestão descentralizada do Programa Bolsa Família', Revista de Administração Pública 49(2), 367-393.

Bardhan, P. \& Mookherjee, D. (2005), 'Decentralizing antipoverty program delivery in developing countries', Journal of Public Economics 89, 675-704.

Barros, R. P. d., Henriques, R. \& Mendonça, R. (2006), O papel das transferências públicas na queda recente da desigualdade de renda brasileira, in R. P. d. Barros, M. M. Foguel \& G. Ulyssea, eds, 'Desigualdade de Renda no Brasil: Uma Análise da Queda Recente', Vol. 2, IPEA, Brasília.

Cameron, A. C. \& Trived, P. K. (2010), Microeconometrics Using Stata - Revised Edition, The Stata Press Publication, Texas.

Cavalcante, P. L. C. (2011), 'Programas de transferência condicionada de renda na América Latina: uma abordagem comparada entre Brasil, México, Chile e Colômbia', Revista do Serviço Público 62(2), 105-118.

Coady, D., Grosh, M. \& Hoddinott, J. (2005), The targeting of transfers in developing countries: review of experiences and lessons. Washington, D. C., World Bank, Discussion Paper n. 0526.

Galasso, E. \& Ravallion, M. (2005), 'Decentralized targeting of an antipoverty program', Journal of Public Economics 89(4), 705-727.

Greene, W. H. (2012), Econometric Analysis, International Edition, 7 edn, Pearson Prentice Hall, New Jersey.

Gujarati, D. N. (2011), Econometria Básica, 5 edn, McGrawHill Bookman, Porto Alegre.

Hu, B., Shao, J. \& Palta, M. (2006), 'Pseudo-R2 in logistic regression model', Statistica Sinica 16, 847-860.

Kerstenetzky, C. L. (2009), 'Redistribuição e desenvolvimento? A economia política do Programa Bolsa Família', Dados - Revista de Ciências Sociais 52(1), 53-83.

McFadden, D. et al. (1973), 'Conditional logit analysis of qualitative choice behavior', Frontiers in Econometrics pp. 105-142. 
Musgrave, R. A. (1971), 'Economics of fiscal federalism', Nebraska Journal of Economics and Business 10(4), 3-13.

Oates, W. E. (1999), 'An essay on fiscal federalism', Journal of Economic Literature $37(3), 1120-1149$.

Pedrozo Jr, E. (2010), Efeitos de elegibilidade e condicionalidade do Programa Bolsa Família sobre a alocação de tempo dos membros do domicílio. Tese de Doutorado em Economia de Empresas, Escola de Economia de São Paulo da Fundação Getúlio Vargas, São Paulo.

Revista Brasileira de Monitoramento e Avaliação (2012). Acesso em: 23 março 2015.

URL: $\quad$ http://aplicacoes.mds.gov.br/sagirmps/ferramentas/docs/RBMAs /RBMA_03.pdf

Silveira Neto, R. M. (2010), Impacto do Programa Bolsa Família sobre a frequência à escola: estimativas a partir de informações da pesquisa nacional por amostra de domicílio (PNAD), in J. A. Castro \& L. Modesto, eds, 'Bolsa Família 2003-2010, Avanços e Desafios', Vol. 2, IPEA, Brasília.

Soares, S., Osório, R. G., Soares, F. V., Medeiros, M. \& Zepeda, E. (2007), Programas de transferência de renda no Brasil, Chile e México: impactos sobre a desigualdade. Brasília, IPEA, 2007, Texto para Discussão, n. 1293.

Soares, S., Ribas, R. P. \& Soares, F. V. (2009), Focalização e cobertura do Programa Bolsa Família: qual o significado dos 11 milhões de famílias? Brasília, IPEA, 2009, Texto para Discussão, n. 1396.

Tavares, P. A., Pazello, E. T., Fernandes, R. \& Camelo, R. d. S. (2009), 'Uma avaliação do Programa Bolsa Família: focalização e impacto na distribuição de renda e pobreza', Pesquisa e Planejamento Econômico 39(1).

Wooldridge, J. M. (2002), Econometric Analysis of Cross Section and Panel Data, The MIT Press, Cambridge, Massachusetts. 


\section{Apêndice A Construção da Variável Renda Familiar Ajustada per capita ex-ante}

No Censo Demográfico 2010, os benefícios do Programa Bolsa Família estão incluídos na variável V6591, juntamente com os rendimentos provenientes de juros de poupança, aplicações financeiras, aluguel, pensão ou aposentadoria de previdência privada, programas sociais ou de transferência de renda, e outras fontes que a pessoa tinha no mês de julho de 2010. Como a identificação das famílias pobres neste estudo exige a informação da renda familiar per capita ex-ante (expurgada do benefício do $\mathrm{PBF}$ ), houve a necessidade de se elaborar uma variável proxy dos benefícios do PBF, a partir da variável V6591, para então se obter uma proxy para a variável "renda familiar ajustada per capita ex-ante". A dedução do valor do benefício exige a proposta de um algoritmo que busque identificar, de maneira razoável, a parcela daqueles rendimentos que lhe corresponde, e o algoritmo aqui utilizado combina elementos presentes nos procedimentos adotados em situação análoga por Pedrozo Jr (2010) e por Barros et al. (2006).

Para tanto, considera-se a informação da variável V6527 ("rendimento mensal total em julho de 2010"), e atribui-se valor igual a zero para os missing values, que correspondem às informações de renda das crianças com idade inferior a 10 anos. A seguir, são excluídos da amostra os indivíduos nas seguintes condições, segundo a variável V0502 ("relação de parentesco ou de convivência com a pessoa responsável pelo domicílio"): agregado, convivente, pensionista, empregado doméstico, parente do empregado doméstico, e individual em domicílio coletivo.

Os beneficiários do Programa Bolsa Família são identificados a partir da variável V0657 (“em julho de 2010, tinha rendimento mensal habitual de Programa Social Bolsa Família ou Programa de Erradicação do Trabalho Infantil $(\mathrm{PETI})^{13 \prime)}$. Atribui-se status de beneficiário a qualquer indivíduo residente em domicílio com ao menos uma pessoa que responda "sim" à pergunta. São excluídos da amostra indivíduos residentes em domicílios que só apresentam "ignorado" como resposta.

A seguir, é construída a proxy dos valores recebidos do PBF a partir da variável V6591, já mencionada, segundo as regras e valores utilizados pelo programa em 2010 e relatados na Tabela 1 deste trabalho. O número de filhos jovens (de até 15 anos, e de 16 ou 17 anos), para cada família, corresponde ao número de indivíduos nessas faixas etárias residentes no domicílio.

Por fim, subtrai-se do rendimento mensal total a proxy de rendimentos individuais oriundos dos benefícios do programa, e atribui-se o valor médio no domicílio desses valores a cada indivíduo nele residente ("renda familiar per capita ajustada ex-ante").

\footnotetext{
${ }^{13}$ A identificação dos beneficiários com a variável V0657 nos leva a considerar também beneficiários do PETI, o que acarretará, em última instância, à superestimação dos vazamentos do PBF. Entretanto, não se espera que essa diferença seja grande, tendo em vista o número baixo de beneficiários do PETI quando comparado ao PBF.
} 
